\title{
The cloud-free global energy balance and inferred cloud radiative effects: an assessment based on direct observations and climate models
}

\author{
Martin Wild ${ }^{1}$ - Maria Z. Hakuba ${ }^{2,3} \cdot$ Doris Folini $^{1} \cdot$ Patricia Dörig-Ott ${ }^{1} \cdot$ Christoph Schär $^{1} \cdot$ Seiji Kato $^{4}$. \\ Charles N. Long ${ }^{5}$
}

Received: 27 April 2018 / Accepted: 16 August 2018 / Published online: 21 August 2018

(c) The Author(s) 2018

\begin{abstract}
In recent studies we quantified the global mean Earth energy balance based on direct observations from surface and space. Here we infer complementary reference estimates for its components specifically under cloud-free conditions. While the clear-sky fluxes at the top of atmosphere (TOA) are accurately known from satellite measurements, the corresponding fluxes at the Earth's surface are not equally well established, as they cannot be directly measured from space. This is also evident in 38 global climate models from CMIP5, which are shown to greatly vary in their clear-sky surface radiation budgets. To better constrain the latter, we established new clear-sky reference climatologies of surface downward shortwave and longwave radiative fluxes from worldwide distributed Baseline Surface Radiation Network sites. 33 out of the 38 CMIP5 models overestimate the clear-sky downward shortwave reference climatologies, whereas both substantial overestimations and underestimations are found in the longwave counterparts in some of the models. From the bias structure of the CMIP5 models we infer best estimates for the global mean surface downward clear-sky shortwave and longwave radiation, at 247 and $314 \mathrm{Wm}^{-2}$, respectively. With a global mean surface albedo of $13.5 \%$ and net shortwave clear-sky flux of $287 \mathrm{Wm}^{-2}$ at the TOA this results in a global mean clear-sky surface and atmospheric shortwave absorption of 214 and $73 \mathrm{Wm}^{-2}$, respectively. From the newly-established diagrams of the global energy balance under clear-sky and all-sky conditions, we quantify the cloud radiative effects not only at the TOA, but also within the atmosphere and at the surface.
\end{abstract}

\section{Introduction}

The global energy balance fundamentally constrains the energy fluxes in the Earth's climate system. Radiative transfer through the atmosphere can be modified by both cloudrelated processes and processes within the cloud-free atmosphere. In the cloud-free atmosphere, the shortwave fluxes

Martin Wild

martin.wild@env.ethz.ch

1 Institute for Atmospheric and Climate Science, ETH Zurich, 8001 Zurich, Switzerland

2 Department of Atmospheric Sciences, Colorado State University, Ft Collins, CO 80523, USA

3 NASA Jet Propulsion Laboratory, California Institute of Technology, Pasadena, CA 91109, USA

4 NASA Langley Research Center, 21 Langley Boulevard, Hampton, VA 23681-2199, USA

5 NOAA ESRL GMD/CIRES, Boulder, CO 80305, USA stemming from the sun can be absorbed and/or scattered by gaseous and solid constituents, such as water vapor and other radiatively active gases as well as aerosols. Radiatively active gases are also mainly responsible for the longwave emission of the cloud-free atmosphere towards space and the Earth's surface. For the quantification of the effects of clouds on the Earth's energy balance, the precise magnitudes of the radiative fluxes both under "all-sky" (including clouds) and "clear-sky" (excluding clouds) conditions need to be known (Ramanathan 1987).

Thanks to the sophisticated satellite observing systems in operation since the turn of the millennium, the radiative fluxes in and out of the climate system at the TOA are now well determined (Loeb et al. 2012, 2018). This allows also an accurate estimation of the impact of clouds on the TOA radiation budget through the comparison of satellite measurements representing all-sky and clear-sky conditions, and an adequate assessment of their representation in climate models (e.g., Potter and Cess 2004; Wang and $\mathrm{Su} 2013$ ). The magnitudes of radiative fluxes at the 
Earth's surface, however, both under all-sky and clear-sky conditions, are not known with the same accuracy, since they cannot be directly measured from satellites (Kiehl and Trenberth 1997; Hatzianastassiou et al. 2005; Wild et al. 2006, 2013; Trenberth et al. 2009; Trenberth and Fasullo 2012; Stephens et al. 2012; L'Ecuyer et al. 2015; Pfeifroth et al. 2018). Similarly, the radiation budgets simulated by the latest generation of global climate models (GCMs) participating in the Coupled Model Intercomparison Project Phase 5 (CMIP5) show large discrepancies already on a global mean basis particularly at the Earth's surface, and this not only under all-sky, but also under clear-sky conditions, as will be shown in the present study.

In previous studies (Wild et al. 2013, 2015) we made an attempt to better constrain the radiative fluxes in the CMIP5 models under all-sky conditions, using to the extent possible the information contained in surface radiation measurement records. In the present, complementary study we specifically focus on the clear-sky radiative fluxes. Thereby, we will make use of clear-sky reference climatologies that we established from the high-quality radiation records measured at worldwide distributed stations from the Baseline Surface Radiation Network (BSRN, Ohmura et al. 1998; Driemel et al. 2018). We will then use these newly established references to assess the clear-sky fluxes simulated by the CMIP5 models.

We will further use the emerging bias structure of the CMIP5 clear-sky fluxes with respect to the BSRN records to infer best estimates for the global mean surface shortwave and longwave clear-sky fluxes. We will then incorporate these estimates, together with TOA flux estimates from satellites, to establish a diagram of the global energy balance under cloud-free conditions, as presented in Fig. 1. By combining these estimates with the corresponding all-sky estimates determined in our earlier studies we will finally quantify the global cloud radiative effects not only at the TOA, but also within the atmosphere and at the surface.

\section{Climate models}

In the present study we assess the clear-sky radiation climatologies as simulated by a variety of GCMs from the Coupled Model Intercomparison Project Phase 5 (CMIP5), which provided the basis for the most recent (5th) IPCC assessment report (IPCC 2013). They correspond to the 43 models listed in Table 1 of Wild et al. (2015), except for the following models which could not, or only partly, be considered in the present study due to incomplete clear-sky

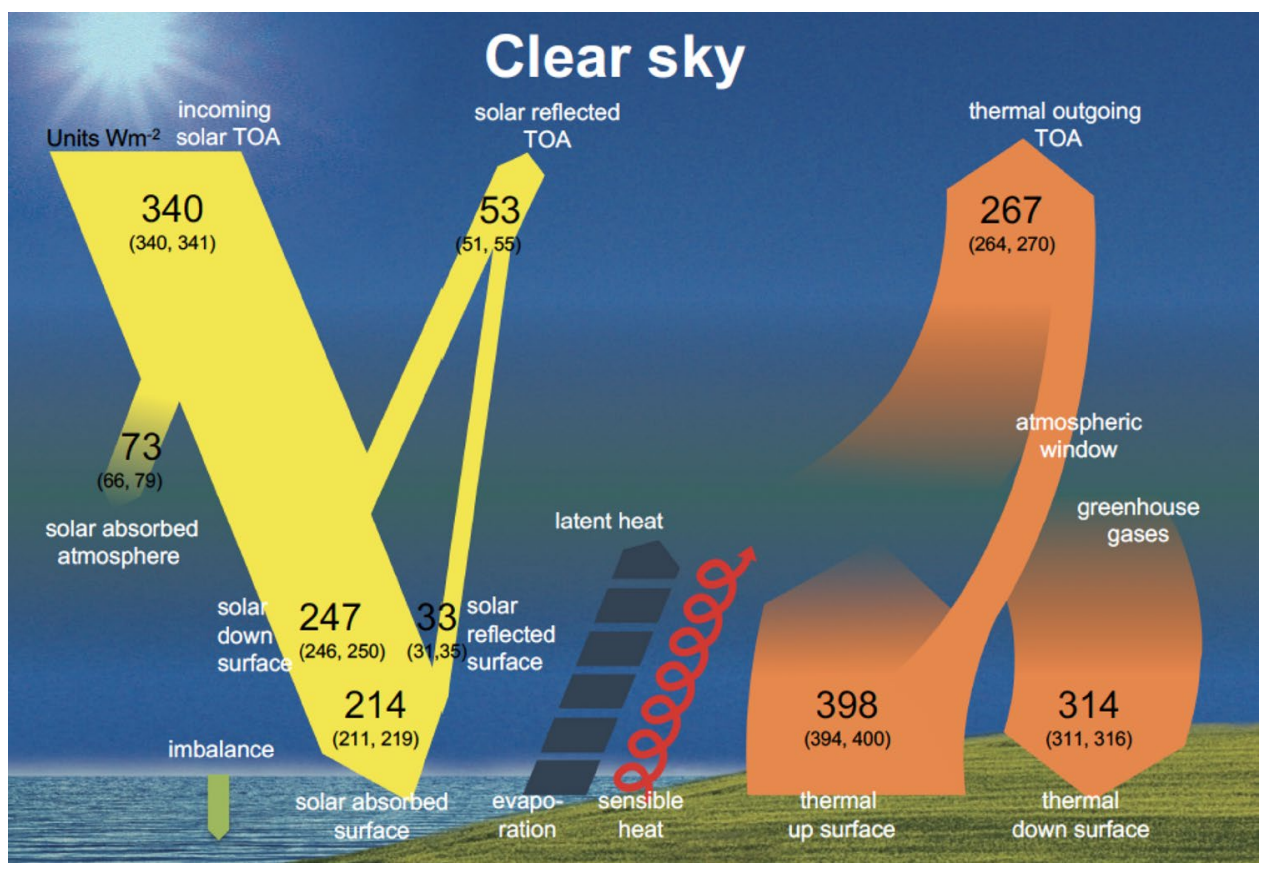

Fig. 1 Schematic representation of the global annual mean energy balance of the Earth under cloud-free conditions. Numbers indicate best estimates for the magnitudes of the globally averaged clear-sky energy balance components together with their uncertainty ranges, representing present day climate conditions at the beginning of the new millennium. Estimates based on discussion in Sect. 6. Units $\mathrm{Wm}^{-2}$. Note that the cloud-free energy balance shown here is not the balance that Earth would achieve in equilibrium when no clouds could form. It rather represents the global mean fluxes as determined solely by removing the clouds but otherwise retaining the entire atmospheric structure (i.e. the GCM representation of clear-sky fluxes, also known as Method II according to Cess and Potter 1987). Thus, the TOA budget is not closed 
datasets: model versions CMCC-CESM, CMCC-CM, CMCC-CMS of the Centro Euro-Mediterraneo per I Cambiamenti Climatici (no surface shortwave and longwave clear-sky fluxes), CNRM-CM5 from the Centre National de Recherches Meteorologiques (wrong partitioning of shortwave clear-sky fluxes into downward and upward components over land), FGOALS-g2 from the Institute of Atmospheric Physics (corrupted surface downward clearsky fluxes at poles, no surface shortwave clear-sky upward fluxes), and two versions of the Community Earth System Model, CESM1-CAM5 and CESM1-CAM5.1-FV2 (no surface clear-sky downward longwave fluxes). This leaves 38 and 37 CMIP5 models for the analysis of the shortwave and longwave clear-sky fluxes, respectively.

As in our previous studies (Wild et al. 2013, 2015) the model-calculated flux climatologies stem from the "historical all forcings" experiments, which aim at reproducing the evolution of climate over the twentieth century as realistically as possible, considering all major natural and anthropogenic radiative forcings. These include changes in atmospheric greenhouse gases, aerosol loadings (tropospheric and stratospheric volcanic), solar output, and land use. Most of the CMIP5 historic experiments cover the period from the mid nineteenth century up to 2005 .

The GCM clear-sky fluxes are determined at every timestep irrespective of the presence of clouds. During cloudy conditions, clear-sky fluxes are calculated by removing the clouds in the radiative transfer calculations, but otherwise retaining the atmospheric input structure (e.g. profiles of water vapor, temperature, aerosols) that prevail during these cloudy conditions. This is also known as "Method II" according to Cess and Potter (1987) and Potter et al. (1992), whereas their definition of "Method I" refers to clear-sky climatologies which are only composed of truly cloud-free episodes. Clear-sky flux climatologies were established from the CMIP5 models as 5-year averages over the final complete years of their "historical all forcings" experiments, which correspond to the years 2000-2004. Since the year to year variations in the model-calculated clear-sky fluxes are small (the median annual variation at the various BSRN sites, defined as difference between the 5 and 95 percentiles, amounts to $2 \mathrm{Wm}^{-2}$ ), a 5 -year mean gives a representative depiction of the model clear-sky flux climatologies at the beginning of the 21 th century. To derive a correction, which ensures an adequate comparison between model-calculated (according to Method II above) and observed (according to Method I) shortwave clear-sky flux climatologies, we additionally made use of the multi-century unforced control simulations of the CMIP5 models, as well as an in-house simulation with the model MPI-ESM-LR (see Sect. 4). The latter allowed to store and investigate the clear-sky fluxes at higher temporal resolution (daily data) than provided by the CMIP5 archive (only monthly data).
A detailed description of the models participating in CMIP5 is provided on the CMIP5 web-pages of the Program for Climate Model Diagnosis and Intercomparison (PCMDI) (http://www-pcmdi.llnl.gov/). From most CMIP5 models multiple simulations of the historic experiments are available, which only differ in their initial conditions (ensemble experiments). However, the different ensemble members from a specific model hardly differ in terms of their clearsky radiative flux climatologies (by less than $1 \mathrm{Wm}^{-2}$ on average), and the results presented in this study were found not to be sensitive to the choice of a particular ensemble member from a specific model. Therefore, results from only one ensemble realization of each model are presented in this study. This also avoids giving too much weight to specific models with large numbers of ensembles.

\section{Clear-sky reference climatologies}

The observational reference data for the clear-sky fluxes at the Earth's surface are derived from the records of the Baseline Surface Radiation Network (BSRN, Ohmura et al. 1998; Driemel et al. 2018). BSRN is a worldwide network of radiation sites measuring at highest possible accuracy with well-calibrated instruments and known accuracy, which can serve as anchor sites for a variety of applications. BSRN became operational in the early 1990s with a few sites and has gradually been growing to contain now more than 60 sites in different climate zones, which report their data to the BSRN Archive at the Alfred Wegener Institute (AWI) (http://www.bsrn.awi.de/). The BSRN data are recorded and stored at high temporal resolution (minute data), which is a prerequisite for the application of clear-sky detection algorithms as outlined below. BSRN sites are further requested to record shortwave radiation not only in terms of its total flux (measured with a pyranometer), but also separately in terms of the direct shortwave flux (measured with a pyrheliometer) and the diffuse shortwave flux (measured with a shaded pyranometer).

The availability of both direct and diffuse measurements is indispensable for the detection of cloud-free conditions, as clouds substantially modify the ratio between these two components. The Long and Ackerman (2000) clear-sky detection algorithm for shortwave radiation that we apply in this study makes use of this behaviour, as well as of the high temporal resolution of the data. Specifically, this algorithm analyses the magnitude and variability of the minute time-series of total (global) and diffuse shortwave irradiance periods to infer clear (i.e. cloudless) sky episodes. The identified clear-sky data at minute resolution are then used on a daily basis to empirically fit functions using the cosine of the solar zenith angle as the independent variable for days that exhibit the minimum amount of 
clear-sky times across the necessary range of solar zenith angles as defined by Long and Ackerman (2000). The fit coefficients are interpolated through time for days that cannot be adequately fitted, and then the coefficients (fitted or interpolated) are used to calculate continuous estimates of the clear-sky downward total, diffuse and direct shortwave radiation. The methodology requires some modification for climates such as the tropical western Pacific characterized by persistent cloudiness as detailed in Long and Gaustad (2004). As shown in Long and Ackerman (2000), the uncertainty of the clear-sky estimates due to interpolation is about of the same magnitude as the total shortwave measurements themselves for the instantaneous values. The long-term averaging of these values as used in the present study significantly decreases the uncertainties. Following the procedure as described above, clear-sky climatologies of surface downward shortwave radiation were produced at $53 \mathrm{BSRN}$ sites which provide multiyear shortwave records that allow to establish climatologies (Table 1) (Hakuba et al. 2017). The periods covered by these reference climatologies do not necessarily exactly match the ones of the model climatologies (which is not a strict requirement due to the non-deterministic nature of the modelling setups), yet both observational and model climatologies can be considered as representative of the beginning of the 21 th century.

The clear-sky detection algorithm for the longwave radiation is based on Long and Turner (2008), and takes into account the temporal variability of downward longwave radiation, as well as the difference between the measured ambient air temperature and effective sky brightness temperature calculated from the longwave measurements. The detected "effective" clear-sky data are used along with the previously detected shortwave clear-sky data to fit functions using collocated air temperature and humidity measurements as the independent variable in the formulation developed by Brutsaert (1975). These longwave detected periods are labelled "effective" clear-sky because the broadband downwelling longwave is insensitive to high, cold, thin clouds, thus the detected clear-sky times represent primarily periods with no low- and mid-level clouds. Similar to the shortwave clear-sky method, the fit coefficients are interpolated through time and used to produce continuous estimations of clear-sky longwave fluxes. Following this procedure, the data availability allowed the construction of clear-sky climatologies of surface downward longwave radiation at $31 \mathrm{BSRN}$ sites (Table 1).

The TOA clear-sky references referred to in this study are obtained from the satellite-based Energy Balanced and Filled (EBAF) dataset from the Clouds and the Earth's Radiant Energy System (CERES, Wielicki et al. 1996) program, CERES-EBAF Edition 4.0 (Loeb et al. 2018).

\section{Shortwave clear-sky fluxes}

\subsection{Global budgets}

Figure 2 shows the global annual mean clear-sky budgets as simulated by 38 CMIP5 GCMs at the surface (bottom panel), within the atmosphere (middle panel) and at the TOA (upper panel). The budgets at the TOA that govern the total amount of clear-sky absorption in the climate system, are to some extent tuned to match the CERES reference value, given at $287 \mathrm{Wm}^{-2}$ for the global mean TOA shortwave clear-sky absorption. Accordingly, the corresponding quantity in the CMIP5 multi-model mean, at $288.6 \mathrm{Wm}^{-2}$, closely matches the CERES reference (Table 2). Between the individual models, this quantity varies in a range of $10 \mathrm{Wm}^{-2}$, with a standard deviation of $2.1 \mathrm{Wm}^{-2}$, and with a maximum deviation of $5 \mathrm{Wm}^{-2}$ from the CERES reference value (Table 2; Fig. 2 upper panel).

No similarly trusted reference values are available for the global mean shortwave absorption under cloudfree conditions at the Earth surface. Accordingly, model estimates differ in a larger range $\left(16 \mathrm{Wm}^{-2}\right)$ and with a larger standard deviation $\left(3.6 \mathrm{Wm}^{-2}\right)$ than their TOA counterparts, despite the absolute values being lower by about 25\% (Table 2; Fig. 2 lower panel). The global mean absorption of shortwave radiation in the cloud-free atmosphere also varies between different models in a range of 11 $\mathrm{Wm}^{-2}$ (Fig. 2, middle panel), which corresponds to $17 \%$ of their absolute values spread around $70 \mathrm{Wm}^{-2}$, and with a standard deviation of $2.9 \mathrm{Wm}^{-2}$ (Table 2).

The large spread amongst the models remains if we consider the downward rather than the absorbed clear-sky fluxes at the surface which can directly be compared to the upward-oriented radiation sensors of the surface stations. In their global means, these clear-sky fluxes vary in a range of $13 \mathrm{Wm}^{-2}$, with a standard deviation of $3.7 \mathrm{Wm}^{-2}$ (Fig. 3 upper panel, Table 2). Interestingly, this intermodel spread is not that much smaller than the all-sky equivalent of the downward shortwave radiation, despite neglecting cloud effects (Fig. 3 lower panel, Table 2).

\subsection{Surface flux assessment}

To better constrain the unsatisfactory large spread in the model calculated shortwave clear-sky fluxes at the surface noted above, we use the clear-sky reference climatologies established from records compiled at $53 \mathrm{BSRN}$ sites (see Sect. 3, Table 1) and perform a pointwise comparison with the corresponding flux fields from the CMIP5 models. Thereby the model-calculated fields of clear-sky downward shortwave radiation were interpolated to the 
Table 1 BSRN observation sites used in this study, alphabetically ordered according to their shortcuts, together with their associated country/region, latitudes (positive north/negative south), longitudes (positive east/negative west), altitudes (m) and their climatological annual means of clear-sky downward shortwave and longwave radiation $\left(\mathrm{Wm}^{-2}\right)$, determined as described in Sect. 3

\begin{tabular}{|c|c|c|c|c|c|c|c|}
\hline Station shortcut & Station name & Country/region & Latitude & Longitude & Altitude & $\begin{array}{l}\text { Clear-sky } \\
\text { SW down }\end{array}$ & $\begin{array}{l}\text { Clear-sky } \\
\text { LW down }\end{array}$ \\
\hline ALE & Alert & Lincoln Sea, Canada & 82.49 & -62.42 & 127 & 126.4 & 174.4 \\
\hline ASP & Alice Springs & Macdonnell Ranges, NT, Australia & -23.798 & 133.888 & 547 & 291.5 & \\
\hline BAR & Barrow & Alaska, USA & 71.323 & -156.607 & 8 & 128.1 & \\
\hline BER & Bermuda & Bermuda & 32.267 & -64.667 & 8 & 260.5 & 347.1 \\
\hline BIL & Billings & Oklahoma, USA & 36.605 & -97.516 & 317 & 251.9 & 310.1 \\
\hline BON & Bondville & Illinois, USA & 40.0667 & -88.3667 & 213 & 241.9 & \\
\hline BOS & Boulder & Colorado, USA & 40.125 & -105.237 & 1689 & 252.5 & \\
\hline BOU & Boulder & Colorado, USA & 40.05 & -105.007 & 1577 & 253.5 & 264.4 \\
\hline BRB & Brasilia & $\begin{array}{l}\text { Brasilia City, Distrito Federal, } \\
\text { Brazil }\end{array}$ & -15.601 & -47.713 & 1023 & 283.8 & 342.8 \\
\hline CAB & Cabauw & The Netherlands & 51.9711 & 4.9267 & 0 & 195.3 & 287.2 \\
\hline CAM & Camborne & United Kingdom & 50.2167 & -5.3167 & 88 & 202.6 & \\
\hline CAR & Carpentras & France & 44.083 & 5.059 & 100 & 222.2 & 300.0 \\
\hline CLH & Chesapeake Light & North Atlantic Ocean, USA & 36.905 & -75.713 & 37 & 249.5 & 309.4 \\
\hline CNR & Cener & Spain, Sarriguren, Navarra & 42.816 & -1.601 & 471 & 231.0 & 290.0 \\
\hline $\mathrm{COC}$ & Cocos Island & Cocos (Keeling) Islands & -12.193 & 96.835 & 6 & 299.4 & \\
\hline DAA & De Aar & South Africa & -30.6667 & 23.993 & 1287 & 273.8 & 299.7 \\
\hline DAR & Darwin & Australia & -12.425 & 130.891 & 30 & 292.5 & 394.9 \\
\hline DOM & Concordia Station, Dome C & Antarctica & -75.1 & 123.383 & 3233 & 160.4 & \\
\hline DRA & Desert Rock & Nevada, USA & 36.626 & -116.018 & 1007 & 263.5 & \\
\hline E13 & Southern Great Plains & Oklahoma, USA & 36.605 & -97.485 & 318 & 251.3 & 309.3 \\
\hline EUR & Eureka & Ellesmere Island, Canadian Arctic & 79.989 & -85.9404 & 85 & 122.7 & \\
\hline FLO & Florianopolis & South Atlantic Ocean, Brazil & -27.6047 & -48.5227 & 11 & 268.6 & 346.9 \\
\hline FPE & Fort Peck & Montana, USA & 48.3167 & -105.1 & 634 & 214.3 & \\
\hline FUA & Fukuoka & Japan & 33.5822 & 130.3764 & 3 & 253.4 & 320.8 \\
\hline GCR & Goodwin Creek & Mississippi, USA & 34.2547 & -89.8729 & 98 & 252.4 & \\
\hline GVN & Georg von Neumayer & Dronning Maud Land, Antarctica & -70.65 & -8.25 & 42 & 155.3 & 180.8 \\
\hline ILO & Ilorin & Nigeria & 8.5333 & 4.5667 & 350 & 285.0 & \\
\hline ISH & Ishigakijima & Japan & 24.3367 & 124.1644 & 6 & 270.4 & 373.9 \\
\hline KWA & Kwajalein & North Pacific Ocean & 8.72 & 167.731 & 10 & 296.6 & 404.6 \\
\hline LAU & Lauder & New Zealand & -45.045 & 169.689 & 350 & 232.2 & \\
\hline LER & Lerwick & Shetland Island, United Kingdom & 60.1389 & -1.1847 & 80 & 167.1 & \\
\hline LIN & Lindenberg & Germany & 52.21 & 14.122 & 125 & 193.9 & 272.5 \\
\hline MAN & Momote & Papua New Guinea & -2.058 & 147.425 & 6 & 299.8 & 407.8 \\
\hline MNM & Minamitorishima & Minami-Torishima, Japan & 24.2883 & 153.9833 & 7 & 277.6 & 378.5 \\
\hline NAU & Nauru Island & Nauru & -0.521 & 166.9167 & 7 & 302.6 & 408.3 \\
\hline NYA & Ny-Ålesund & Ny-Ålesund, Spitsbergen & 78.925 & 11.93 & 11 & 125.4 & 215.4 \\
\hline PAL & Palaiseau, SIRTA Observatory & France & 48.713 & 2.208 & 156 & 206.7 & 285.4 \\
\hline PAY & Payerne & Switzerland & 46.815 & 6.944 & 491 & 214.5 & 277.2 \\
\hline PSU & Rock Springs & Pennsylvania, USA & 40.72 & -77.9333 & 376 & 241.6 & \\
\hline PTR & Petrolina & Brazil & -9.068 & -40.319 & 387 & 289.5 & 361.4 \\
\hline REG & Regina & Canada & 50.205 & -104.713 & 578 & 211.6 & 236.4 \\
\hline SAP & Sapporo & Japan & 43.06 & 141.3286 & 17 & 228.5 & 277.2 \\
\hline SBO & Sede Boqer & Israel & 30.8597 & 34.7794 & 500 & 265.2 & 305.9 \\
\hline SMS & São Martinho da Serra & Brazil & -29.4428 & -53.8231 & 489 & 268.4 & \\
\hline SOV & Solar Village & Saudi Arabia & 24.91 & 46.41 & 650 & 279.0 & \\
\hline SPO & South Pole & Antarctica & -89.983 & -24.799 & 2800 & 141.2 & 87.6 \\
\hline
\end{tabular}


Table 1 (continued)

\begin{tabular}{|c|c|c|c|c|c|c|c|}
\hline Station shortcut & Station name & Country/region & Latitude & Longitude & Altitude & $\begin{array}{l}\text { Clear-sky } \\
\text { SW down }\end{array}$ & $\begin{array}{l}\text { Clear-sky } \\
\text { LW down }\end{array}$ \\
\hline SXF & Sioux Falls & South Dakota, USA & 43.73 & -96.62 & 473 & 231.5 & \\
\hline SYO & Syowa & Cosmonaut Sea, Antarctica & -69.005 & 39.589 & 18 & 159.1 & 182.4 \\
\hline TAM & Tamanrasset & Algeria & 22.7903 & 5.5292 & 1385 & 297.3 & \\
\hline TAT & Tateno & Japan & 36.0581 & 140.1258 & 25 & 252.7 & 306.8 \\
\hline TIK & Tiksi & Siberia, Russia & 71.5862 & 128.9188 & 48 & 133.3 & \\
\hline TOR & Toravere & Estonia & 58.254 & 26.462 & 70 & 173.1 & \\
\hline XIA & Xianghe & China & 39.754 & 116.962 & 32 & 243.6 & \\
\hline
\end{tabular}

coordinates of the BSRN stations taking into account the four distance-weighed surrounding grid points. The random error induced by the comparison of point observations with gridded shortwave flux products with a resolution of $1^{\circ}$ as typically found in GCMs has been estimated by Hakuba et al. $(2013,2014)$ to be on the order of 3 $\mathrm{Wm}^{-2}$ on a climatological timescale, which is attributed to the subgrid-scale variability not resolved by the GCM grid. This applies for all-sky fluxes and should be rather an upper limit for clear-sky fluxes due to their spatially smoother fields.

The comparison is complicated by the fact that the monthly shortwave clear-sky BSRN reference climatologies are derived from measurements under truly cloud-free conditions, whereas the GCM clear-sky fluxes are calculated continuously at every time-step solely by removing the clouds, yet otherwise retaining the prevailing atmospheric composition (e.g. water vapor, temperature, aerosols) during the cloudy conditions. As mentioned in Sect. 2, the former method of determining the clear-sky fluxes is also known in the literature as Method I, whereas the latter is referred to as Method II (Cess and Potter 1987; Potter et al. 1992). These different definitions of clearskies in models and observations give rise to potentially spurious biases in the GCMs with respect to the reference climatologies due to the additional sampling of clear-sky fluxes calculated under atmospheric conditions representative for cloudy situations. Thereby, the different sampling may result in a wet bias in the GCMs compared to the clear-sky reference climatologies, which may induce some spurious additional shortwave atmospheric absorption, thus potentially leading to downward clear-sky shortwave fluxes that are biased artificially somewhat low compared to "true" clear-sky conditions. To obtain an estimate of the magnitude of this potential spurious sampling bias, an obvious procedure would be to compose clear-sky climatologies from the model fluxes only out of situations when true clear-sky conditions prevail. However, this would require access to raw model output at high temporal resolution (ideally at the model time step), yet this is not available from the CMIP5 archive. To nevertheless get a sense of whether the different definitions of clear-skies in models and observations could be of any relevance, we applied the following methodology (Ott 2017): We took from all CMIP5 models used in the present study monthly data from their very long unforced control runs, which typically cover many centuries of integration. Within these multi-century simulations of each model, we searched for the specific month with the least cloud amount, for each month of the year separately (i.e. the January with the least cloud amount out of all Januarys in the control run (typically several hundreds), and similar for each other month of the year through to December). The aim thereby was to approximate as best as we can on a monthly basis true clear-sky conditions. We then took the associated model clear-sky fluxes of these particularly cloud-free months, and compared them to the corresponding long term climatological mean clear-sky fluxes as averaged over the entire control run. This can give an idea to what extent the model-calculated monthly fluxes under as cloudless as possible conditions deviate from the corresponding clearsky fluxes calculated under all types of cloud conditions. These deviations have been determined for each model at each BSRN station, and were subsequently used as corrections to adjust the simulated downward shortwave flux climatologies individually for each model and each station. On average, the deviations were found to be relatively modest, on the order of $2 \mathrm{Wm}^{-2}$, with the clear-sky fluxes of the months with lowest cloudiness systematically slightly higher than under all type of cloud conditions, as expected due to the dryer atmosphere of the former.

We had also the chance to double check the magnitude of this adjustment further, by analysing daily rather than monthly data from a 150-year long control simulation that we performed in-house with one particular model, the MPIESM-LR. Thereby we compared model-calculated clearsky fluxes from the most cloudless days with the respective clear-sky fluxes averaged over all corresponding days from this simulation, for each day of the year. A similar deviation on the order of $2 \mathrm{Wm}^{-2}$ was obtained on average over all 
Fig. 2 Global annual mean clear-sky shortwave radiation budgets of the total climate system (Top of Atmosphere), of the atmosphere (atmospheric absorption) and at the surface (surface absorption) in 38 GCMs participating in the Coupled Model Intercomparison Project Phase 5 (CMIP5). Averages taken over the period 2000-2004 of the "historical all forcings" experiments. Clearsky fluxes in climate models are determined using Method II according to Cess and Potter (1987). Units $\mathrm{Wm}^{-2}$
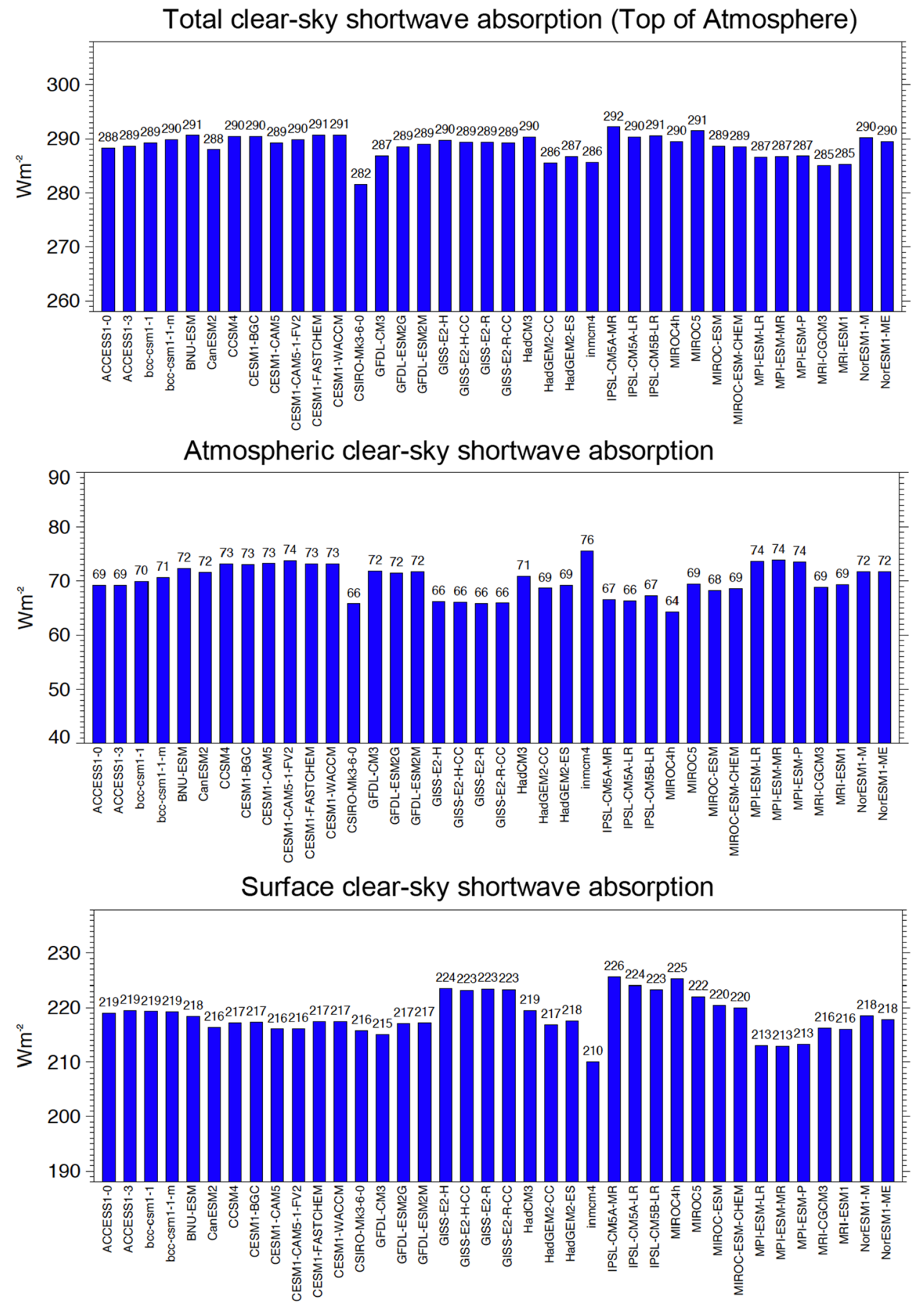

BSRN sites. This increases our confidence in the magnitude of this spurious sampling bias, and in the associated adjustments we applied.

Model-calculated climatologies of the annual cycles of downward surface shortwave clear-sky radiation from the 38 CMIP5 models, slightly adjusted according to the above procedure to ensure a proper comparison with the reference climatologies, are compared in Fig. 4 with the BSRN reference climatologies at 53 stations. In Fig. 4a the mean annual cycles of the 38 models are shown in red, whereas the annual cycles of the BSRN reference climatologies are given in black. Figure $4 \mathrm{~b}$ displays the associated differences between the simulated and observed mean annual cycles for each model. Note the smooth shapes of the annual cycles in Fig. 4a which are characteristic for clear-sky climatologies. Overall the models reproduce the reference annual cycles reasonably well, with monthly biases of no more than 10-20 $\mathrm{Wm}^{-2}$. Only at a few stations, large differences can be noted, 
Table 2 Global annual mean estimates of the magnitude of various energy balance components under clear-sky and all-sky conditions at the TOA, within the atmosphere and at the surface

\begin{tabular}{|c|c|c|c|c|}
\hline Energy balance component & $\begin{array}{l}\text { Reference } \\
\text { estimates }\end{array}$ & $\begin{array}{l}\text { CMIP5 multi- } \\
\text { model mean }\end{array}$ & CMIP5 model range & $\begin{array}{l}\text { CMIP5 model } \\
\text { SD }\end{array}$ \\
\hline \multicolumn{5}{|l|}{ TOA } \\
\hline Solar down TOA & 340 & 341.3 & 3.4 & 0.8 \\
\hline Solar up all-sky TOA & -100 & -102.0 & 12.6 & 3.1 \\
\hline Solar net all-sky TOA & 240 & 239.2 & 11.2 & 3.0 \\
\hline Solar up clear-sky TOA & -53 & -52.6 & 11.2 & 2.3 \\
\hline Solar net clear-sky TOA & 287 & 288.6 & 10.6 & 2.1 \\
\hline Solar CRE TOA & -47 & -49.3 & 14.0 & 3.5 \\
\hline Thermal up all-sky TOA & -239 & -238.0 & 11.7 & 2.9 \\
\hline Thermal up clear-sky TOA & -267 & -263.3 & 12.9 & 3.3 \\
\hline Thermal CRE TOA & 28 & 24.9 & 12.6 & 3.5 \\
\hline Net CRE TOA & -19 & -24.1 & 15.5 & 3.9 \\
\hline \multicolumn{5}{|l|}{ Atmosphere } \\
\hline Solar net all-sky atmosphere & 80 & 74.7 & 9.9 & 2.8 \\
\hline Solar net clear-sky atmosphere & 73 & 70.1 & 11.3 & 2.9 \\
\hline Solar CRE atmosphere & 7 & 4.3 & 8.8 & 1.6 \\
\hline Thermal net all-sky atmosphere & -183 & -179.8 & 22.5 & 3.8 \\
\hline $\begin{array}{l}\text { Thermal net clear-sky atmos- } \\
\text { phere }\end{array}$ & -183 & -179.1 & 15.0 & 2.9 \\
\hline Thermal CRE atmosphere & 0 & -0.5 & 19.5 & 3.5 \\
\hline Net CRE atmosphere & 7 & 4.7 & 18.9 & 4.1 \\
\hline \multicolumn{5}{|l|}{ Surface } \\
\hline Solar down all-sky surface & 185 & 189.6 & 15.8 & 4.7 \\
\hline Solar up all-sky surface & -25 & -24.6 & 10.5 & 2.3 \\
\hline Solar net all-sky surface & 160 & 165.0 & 12.2 & 3.8 \\
\hline Solar down clear-sky surface & 247 & 249.7 & 13.3 & 3.6 \\
\hline Solar up clear-sky surface & 33 & 31.1 & 12.8 & 2.9 \\
\hline Solar net clear-sky surface & 214 & 218.5 & 15.5 & 3.6 \\
\hline Solar CRE surface & -54 & -53.5 & 16.7 & 4.1 \\
\hline Thermal down all-sky surface & 342 & 340.1 & 18.5 & 4.3 \\
\hline $\begin{array}{l}\text { Thermal up all-sky/clear-sky } \\
\text { surface }\end{array}$ & -398 & -398.7 & 10.7 & 2.6 \\
\hline Thermal net all-sky surface & -56 & -58.6 & 15.7 & 3.2 \\
\hline Thermal down clear-sky surface & 314 & 314.7 & 25.8 & 5.5 \\
\hline Thermal net clear-sky surface & -84 & -83.9 & 15.9 & 3.7 \\
\hline Thermal CRE surface & 28 & 25.3 & 13.3 & 3.3 \\
\hline Net CRE surface & -26 & -28.6 & 24.4 & 4.8 \\
\hline
\end{tabular}

Given are the reference estimates, together with the CMIP5 model estimates in terms of their multi-model means, their ranges and their standard deviations (SD). Clear-sky reference estimates and Cloud Radiative Effects (CRE) derived in the present study, all-sky reference estimates from Wild et al. (2015). TOA fluxes derived from CERES-EBAF (Loeb et al. 2018). Units $\mathrm{Wm}^{-2}$. Clear-sky model and reference estimates determined following Method II according to Cess and Potter (1987) mostly in the summer months with high absolute values. Substantial model spread can be seen at desert sites which are heavily influenced by aerosols [ilo: Ilorin (Nigeria), tam: Tamanrasset (Algeria), sov: Solar Village (Saudi Arabia)].

The climatological annual mean differences between model-calculated and observed downward surface shortwave clear-sky radiation at each of the 53 BSRN sites are shown in Fig. 5. The blue bars denote multi-model mean differences between the model-calculated and reference clear-sky climatologies at each individual BSRN station. The spread of model-calculated values at each site is further indicated by vertical lines covering \pm one standard deviation, and by the maximum positive and negative model biases given as triangle symbols. There is an overall tendency that the models overestimate the downward surface shortwave clear-sky fluxes compared to the BSRN references, with a multi-model 
Fig. 3 Global annual mean downward shortwave radiation at Earth's surface under present day climate calculated by 38 CMIP5 models under clearsky conditions (upper panel) and under all-sky conditions (lower panel). Averages taken over the period 2000-2004 of the "historical all forcings" experiments. Clear-sky fluxes are determined using Method II according to Cess and Potter (1987). Units $\mathrm{Wm}^{-2}$

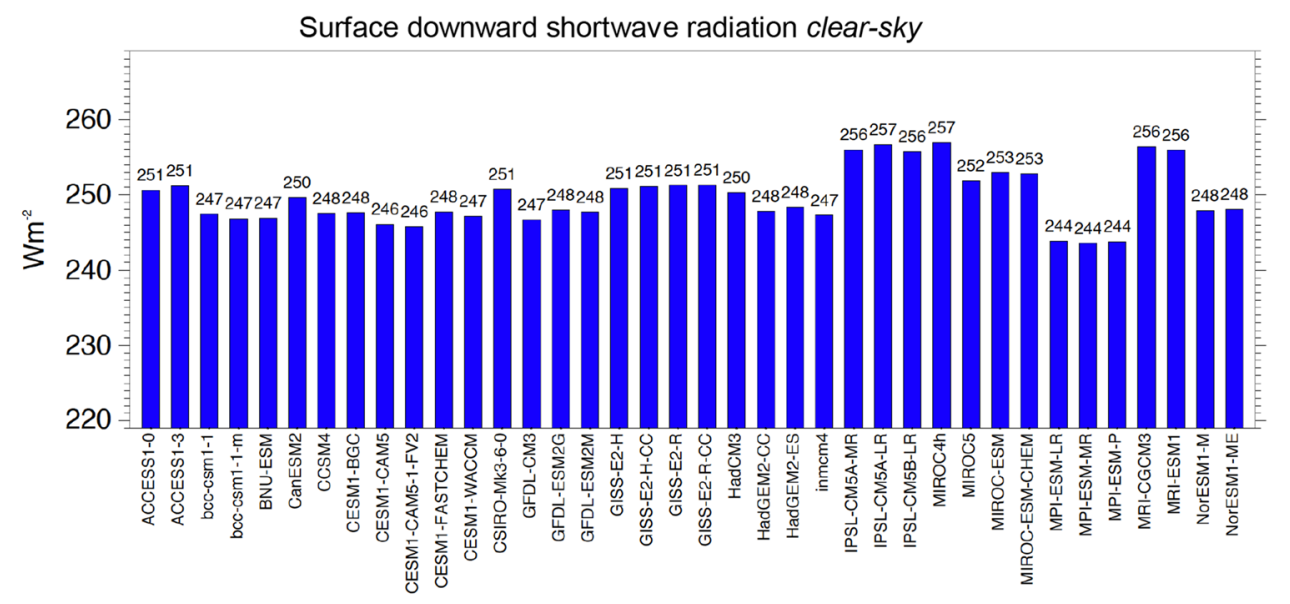

Surface downward shortwave radiation all-sky

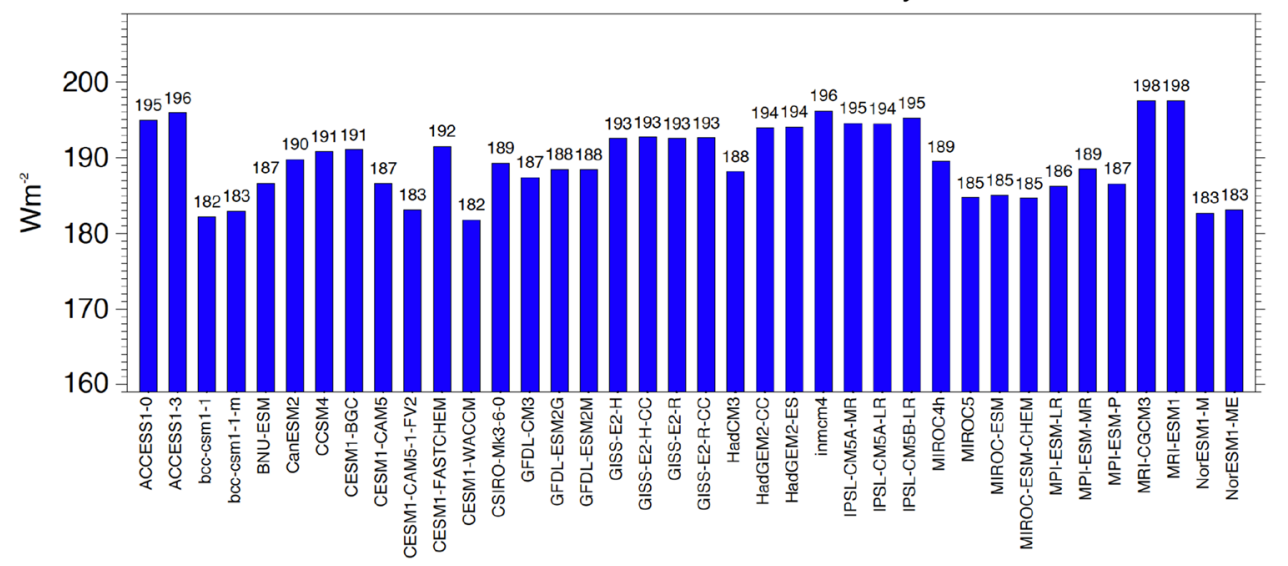

mean overestimation at 35 out of the 53 sites (two-third of the sites). The multi-model mean and median overestimation with respect to the 53 sites is 2.9 and $2.3 \mathrm{Wm}^{-2}$, respectively. There is, however, a considerable fraction, namely 20 sites with multi-model mean biases of no more than 1 $\mathrm{Wm}^{-2}$. This is remarkable given the complex processing that stands behind both model and reference data. At two sites, both located in Brazil (brb and ptr), the multi-model mean differences are particularly high. Although there is the possibility that the models underestimate the absorption by aerosols from biomass burning in these areas we cannot entirely rule out the possibility of a measurement problem at these remote sites. Without considering these two sites, the abovementioned multi-model mean bias reduces by $0.7 \mathrm{Wm}^{-2}$ to $2.3 \mathrm{Wm}^{-2}$, whereas the median bias is hardly affected.

The overall biases of the individual CMIP5 models when averaged over all 53 sites are given in Fig. 6. They largely vary between models, in a range of $13 \mathrm{Wm}^{-2}$, which is not unexpected given the large model discrepancies already in their global mean downward surface shortwave clear-sky radiation (c.f. Fig. 3 upper panel). Most models (32 out of 38) show an overestimation. Averaged over all 38 models, this overestimation amounts to $2.9 \mathrm{Wm}^{-2}$, while the median model overestimation is $2.2 \mathrm{Wm}^{-2}$. Again, excluding the two Brazilian sites would reduce the overestimation by about $0.7 \mathrm{Wm}^{-2}$. It is also noteworthy that more than half of the models show an overall bias compared to the BSRN references of no more than $2 \mathrm{Wm}^{-2}$. The overestimation of the downward surface shortwave clear-sky radiation has been a long-standing issue in climate models, as inferred in earlier studies from fewer observational references and older models compared to the present study (Wild et al. 1995, 1998, 2006). An underestimation of water-vapor absorption in the GCM radiation codes, related to uncertainties in the spectroscopic absorption coefficients and the formulation of the near-infrared water vapor continuum, as well as inaccuracies in the representation of aerosol characteristics and burdens have been put forward as potential causes for the overestimation of the downward surface shortwave clear-sky radiation (Wild et al. 1998; Morcrette 2002; Pincus et al. 2015; Paynter and Ramaswamy 2012, 2014; Radel et al. 2015). This is also in line with findings of the Continual Intercomparison of Radiation Codes (CIRC, Oreopoulos and Mlawer 2010) and preceding radiation code intercomparison projects (Fouquart et al. 1991). While these intercomparison 
(a)
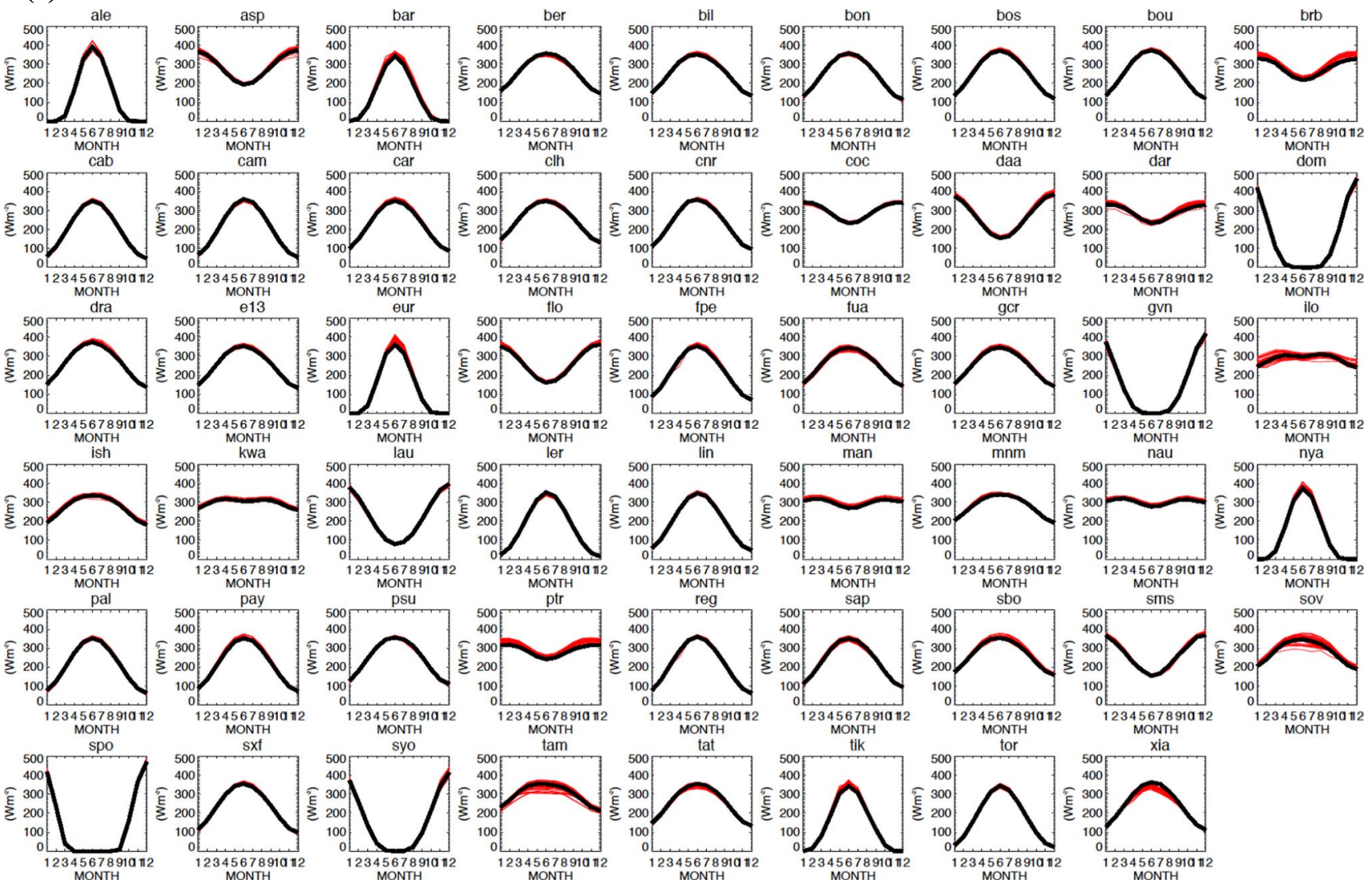

(b)
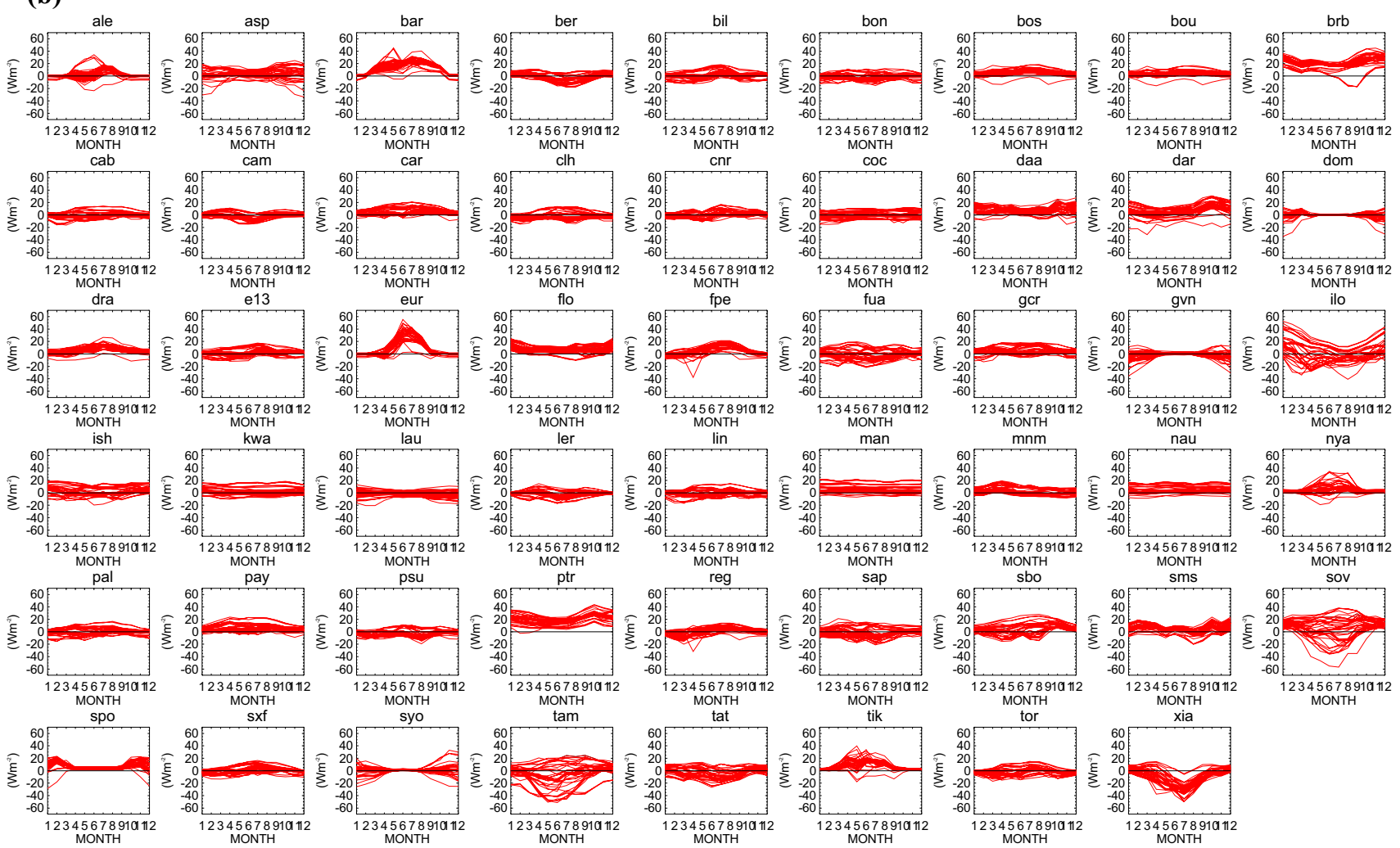

123456678919 1112 
४Fig. 4 a Annual cycles of clear-sky downward surface shortwave radiation climatologies measured at 53 BSRN sites (black lines) and simulated by 38 CMIP5 climate models (red lines). b Differences between the individual model-calculated and observed annual cycles. Model and reference climatologies representative for the beginning of the 21th century. Station abbreviations explained in Table 1. Units $\mathrm{Wm}^{-2}$

projects were useful to identify radiation codes which do not adequately represent well-established radiation physics [e.g., some radiation codes entirely neglect the $\mathrm{N}_{2} \mathrm{O}$ and $\mathrm{CH}_{4}$ absorption (Collins et al. 2006)], they may not be able to nail down uncertainties induced by incompletely understood physics such as aspects of the water vapor continuum or aerosol optical properties. Additional biases in the model-calculated downward surface shortwave clear-sky radiation could potentially be introduced by inadequacies in the simulated amount of water vapor (precipitable water) in the CMIP5 model atmospheres, which is used as input to the radiation schemes. Indeed there is recent evidence that the CMIP5 atmosphere are globally too dry, on average by about $6 \%$ when compared to satellite-derived references (Takahashi 2018). However, the impact of a dry bias of this magnitude on the downward surface shortwave clear-sky radiation is likely less than $1 \mathrm{Wm}^{-2}$ (Wild 2009).

\subsection{Best estimate for the global mean downward surface shortwave clear-sky radiation}

We now make use of the bias structure of the CMIP5 models with respect to the BSRN references to infer a best estimate for the global mean downward surface shortwave clear-sky radiation. We thereby apply the methodology presented in Wild et al. $(2013,2015)$ for all-sky fluxes now to the clear-sky fluxes, and relate the diverging values in global mean downward surface shortwave clear-sky radiation of the various CMIP5 models (as given in Fig. 3) to their respective biases (as given in Fig. 6). Therefore, in Fig. 7, each cross represents one CMIP5 model with its global annual mean downward surface shortwave clear-sky radiation on the vertical axis and its overall climatological bias in this quantity compared to the 53 BSRN sites on the horizontal axis. A very tight connection between the global means and the corresponding biases of the downward surface shortwave clear-sky radiation calculated by the various models is evident, as reflected in a high correlation coefficient of 0.94 . Thus, generally, the more a climate model overestimates the downward surface shortwave clearsky radiation compared to the BSRN references, the higher is also its corresponding global mean value. A linear regression can then be used to determine the hypothetical global mean value that would correspond to a zero bias against the observational references (dashed lines in Fig. 7). The value that fits to the zero bias according to the linear regression is 246.6

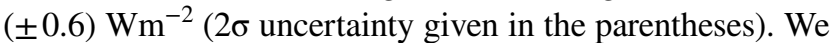

thus take this value as our best estimate for the global annual mean downward surface shortwave clear-sky radiation. Note that in the bias calculations the two suspicious Brazilian sites are included. Excluding these two sites puts the best estimate to $247.3( \pm 0.6) \mathrm{Wm}^{-2}$. This suggests a value near $247 \mathrm{Wm}^{-2}$ as best estimate for the global annual mean downward surface shortwave clear-sky radiation. We further tested two different ways of calculating the regression in Fig. 7, namely a y-least squares and an orthogonal regression, but this had only a marginal influence of less than $0.2 \mathrm{Wm}^{-2}$ on the best estimate derived here.

Unlike in the all-sky estimations in Wild et al. (2013, 2015), we cannot use the independent reference dataset from the Global Energy Balance Archive (GEBA, Wild et al. 2017) to doublecheck the robustness of our method with respect to the station distribution, as the observational records in GEBA are only available at monthly resolution and thus do not allow for the establishment of clear-sky climatologies. In Wild et al. $(2013,2015)$ we could show that for all-sky conditions our regression method to obtain the best estimates of the global mean downward fluxes is fairly robust with respect to the choice of independent reference datasets with differing station distributions. Robust results are expected from our regression method if no major common systematic geographical dependencies are present in the bias structures of the simulated flux climatologies, which could be missed by the BSRN network. We did not find any such dependencies in the clear-sky biases amongst the various CMIP5 models, such as latitudinal dependencies, differences in biases in polar versus tropical sites, or sites in maritime versus terrestrial environments etc., with the one exception of the outlier biases at the two Brazilian sites mentioned above. Therefore we believe that also our clear-sky estimates should be fairly robust, even though we cannot rule out the possibility that undetected outstanding biases in undersampled regions could affect the results.

As in our previous study (Wild et al. 2015), to obtain a conservative uncertainty range for our best estimate, we expand the $2 \sigma$ regression uncertainty range given above to additionally cover all global mean clear-sky estimates from those GCMs which show only marginal biases compared to the surface stations. This accounts for the fact that any global mean estimate stemming from a GCM with only marginal overall biases against the surface sites strictly cannot be disqualified by our approach. Specifically, in Fig. 7 we note also global mean clear-sky downward solar radiation values spreading from 246 to $250 \mathrm{Wm}^{-2}$ which belong to GCMs with marginal overall biases (defined here as smaller than $1 \mathrm{Wm}^{-2}$ ), and which accordingly defines the uncertainty range of this quantity in Fig. 1. 
Fig. 5 Multi-model mean biases (model-observations) in annual mean downward surface clear-sky shortwave radiation at 53 different BSRN sites (blue bars). The spread of individual model biases is further indicated with a vertical line covering \pm one standard deviation, and with the maximum positive and negative model biases given as triangle symbols. Station abbreviations explained in Table 1. Units $\mathrm{Wm}^{-2}$
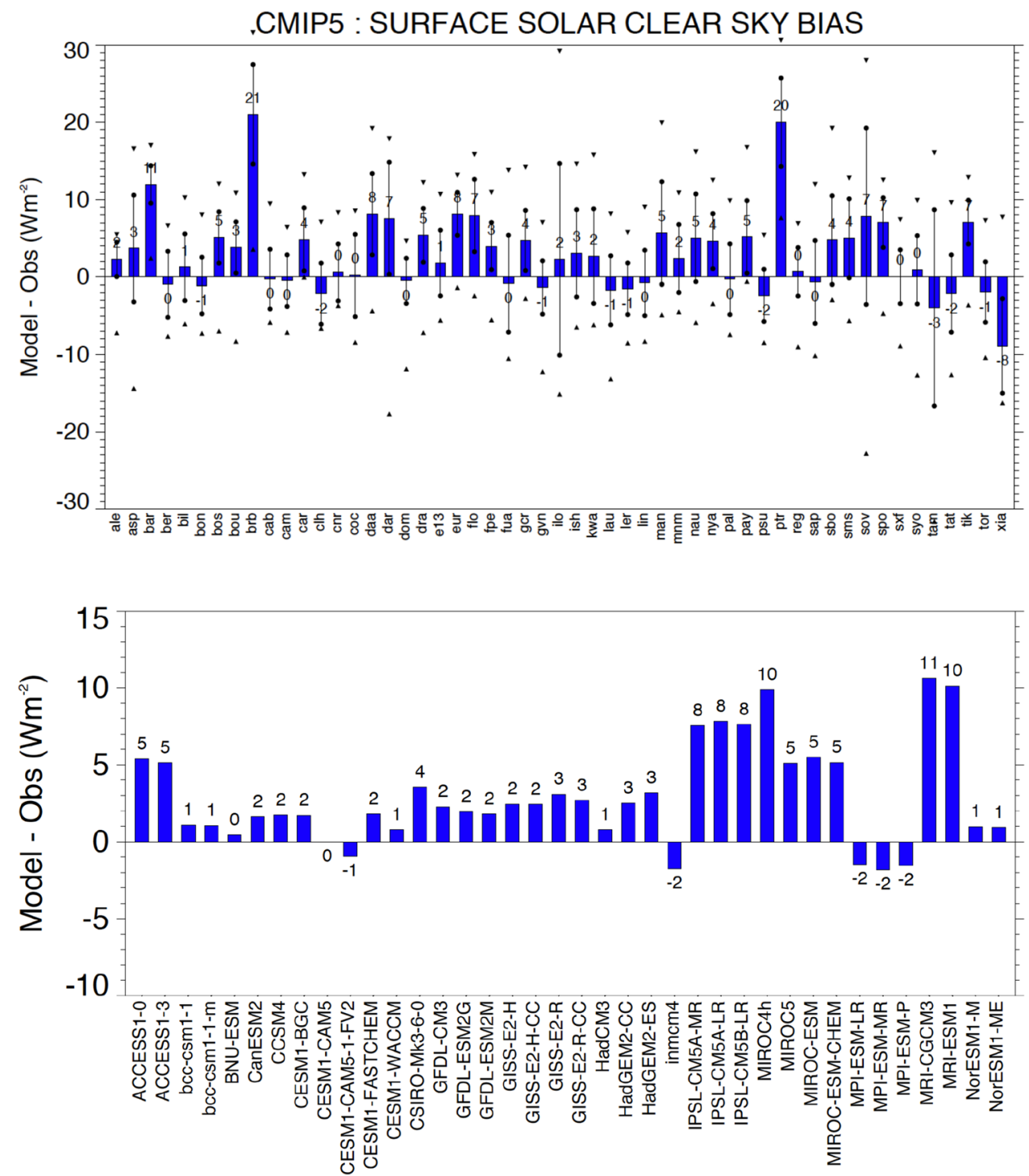

Fig. 6 Biases (model-observations) in climatological annual mean downward clear-sky shortwave radiation at Earth's surface calculated in 38 CMIP5 models averaged over 53 BSRN sites. Units $\mathrm{Wm}^{-2}$

\section{Longwave clear-sky fluxes}

\subsection{Global budgets}

Figure 8 displays the global annual mean net longwave budgets of 37 CMIP5 models for cloud-free conditions at the TOA (outgoing longwave radiation, OLR, upper panel), within the atmosphere (middle panel) and at the Earth's surface (lower panel).

The multi-model global annual mean of the clear-sky OLR is $263 \mathrm{Wm}^{-2}$, which is close to the estimate based on earlier CERES product releases (Ed 2 SYN1deg-Month) of $264 \mathrm{Wm}^{-2}$ (Kato et al. 2013), which might have been used as tuning target during model developments, yet somewhat lower than more recent CERES reference estimates of 266 and $268 \mathrm{Wm}^{-2}$ based on CERES Editions 2.6r and 4.0 , respectively. The global mean clear-sky OLR varies between the 37 CMIP5 models in a range of $13 \mathrm{Wm}^{-2}$ (Fig. 8 upper panel, Table 2). Again, this range is larger in the clear-sky longwave budget at the Earth's surface $\left(16 \mathrm{Wm}^{-2}\right.$, Fig. 8 lower panel, Table 2), where no generally accepted global reference estimates exist. Finally, the atmospheric clear-sky longwave budget of the 37 models is displayed in Fig. 8 (middle panel).

The clear-sky component in the longwave that can be directly compared with surface observations is the surface downward longwave clear-sky radiation. Global annual means of this quantity for each CMIP5 model are shown in Fig. 9 (upper panel). Compared to the net longwave clearsky radiation shown in Fig. 8 (lower panel) the discrepancies amongst the model-calculated global means is further enhanced, now covering a dissatisfactory large range of 26 $\mathrm{Wm}^{-2}$, with a standard deviation of $5.5 \mathrm{Wm}^{-2}$ (Fig. 9 upper panel, Table 2). This spread is even larger than in the corresponding all-sky global means of the same component, 


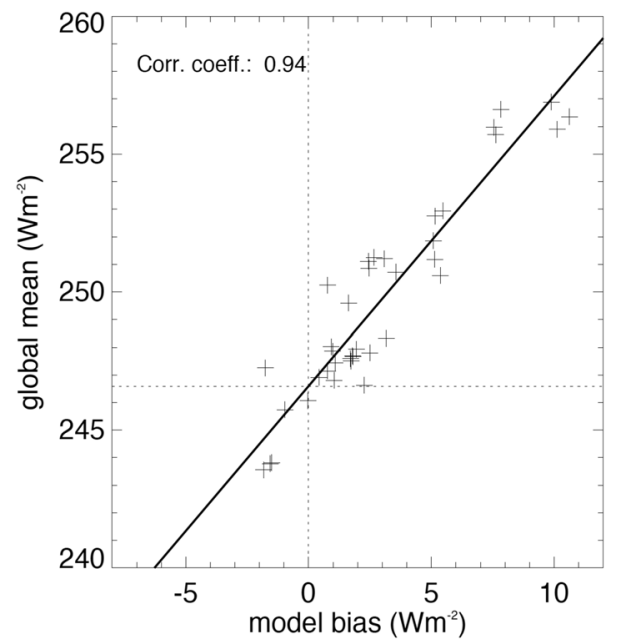

Fig. 7 Global annual mean surface downward shortwave clear-sky radiation of 38 CMIP5 models (given as crosses) on the vertical axis versus their respective overall biases compared to 53 BSRN references on the horizontal axis. A "best estimate" for the surface downward shortwave clear-sky radiation is inferred at the intersect between the linear regression line and the zero bias line. Units $\mathrm{Wm}^{-2}$

where the model spread covers a smaller range and standard deviation of 19 and $4.3 \mathrm{Wm}^{-2}$, respectively (Fig. 9 lower panel, Table 2). This suggests that cloud effects may help to mask some of the discrepancies found in the longwave clearsky fluxes simulated by the various CMIP5 models. This issue has already been noted in earlier generations of climate models (AMIPII, CMIP3) (Wild 2008), and suggests that the longwave emission from the cloud-free atmosphere towards the Earth surface is a major cause for the inter-model differences seen in the (all-sky) downward longwave radiation.

\subsection{Surface flux assessment}

In the following, the surface downward longwave clear-sky radiation fields of the CMIP5 GCMs are compared to the BSRN-derived clear-sky climatologies (c.f. Sect. 3). As with the shortwave, also the longwave clear-sky flux fields in the climate models stem from clear-sky calculations at each timestep, solely by removing the clouds if present, but otherwise retaining the atmospheric temperature and humidity structure (Method II according to Cess and Potter 1987), thus not only taking into account the atmospheric structure under true cloud-free conditions. However, unlike for the shortwave clear-sky assessment in Sect. 4.2, this states no problem for the comparison with the longwave BSRN reference climatologies. This is due to the fact that the algorithm that derives longwave clear-sky fluxes from the BSRN sites uses continuous measurements of air temperature and humidity regardless of whether clouds are present or not (Long and Turner 2008). Thus, the atmospheric conditions that enter the reference estimates are directly comparable to the ones that enter the GCM radiation codes, as both align with Method II, and thus there is no sampling issue. Therefore, unlike in the shortwave, no systematic sampling biases are apparent for the longwave clear-sky fluxes, and no further adjustments are required for an appropriate comparison of the simulated fluxes with the BSRN references.

The simulated climatological mean annual cycles of downward surface longwave clear-sky radiation from the 37 CMIP5 models are compared in Fig. 10 with the BSRN reference climatologies at the 31 stations where such reference climatologies could be established (see Sect. 3, Table 1). In Fig. 10a, the annual cycles of the models are again shown in red, whereas the BSRN reference climatologies are given in black. The associated differences between the model-calculated and observed annual cycles are displayed in Fig. 10b. As in the shortwave (Fig. 4), the models overall reproduce the BSRN annual cycles reasonably well. This gives confidence in both model-simulated and observation-derived fluxes, which are completely independently obtained.

The multi-model mean biases in downward surface longwave clear-sky radiation at each of the $31 \mathrm{BSRN}$ sites are shown in Fig. 11 as blue bars in terms of their climatological annual mean biases. As in Fig. 5, the spread of modelcalculated values at the single sites is further indicated by vertical lines covering \pm one standard deviation and by the maximum positive and negative model biases given as triangle symbols. At two-thirds of the stations, the multi-model mean bias is within $3 \mathrm{Wm}^{-2}$ (blue bars in Fig. 11). The mean and median of the multi-model mean biases over all sites correspond to 1.1 and $0.9 \mathrm{Wm}^{-2}$, respectively. This is remarkable given the amount of processing that went into the generation of both model-simulated and reference data.

Note that there are indications, that the official scale for longwave radiation issued by the World Meteorological Organization (WMO) based on the World Infrared Standard Group (WISG) might somewhat underestimate the downward longwave radiation measured by the pyrgeometers, and may need to be recalibrated in the future (Nyeki et al. 2017). This could potentially lead to surface downward and upward longwave fluxes which are higher by a few $\mathrm{Wm}^{-2}$. Until this issue is completely settled, which will require additional investigations to enhance the preliminary findings from so far four sites as well as the approval and adaptation by WMO and thus may take several years, the WISG scale will remain the reference for longwave measurements in the BSRN network.

Overall climatological mean biases in downward surface longwave clear-sky radiation of the 37 individual CMIP5 models obtained by averaging the biases over all sites are shown in Fig. 12. A large spread in the overall biases can be seen amongst the models, ranging from +10 to $-12 \mathrm{Wm}^{-2}$. As with the shortwave biases presented in Fig. 6, this large spread is not surprising, considering the 
Fig. 8 Global annual mean longwave radiation budgets for clear-sky conditions calculated by 37 CMIP5 models for present day climate (baseline 2000-2004). Net longwave radiation at the surface (lower panel), within the atmosphere (middle panel), and emitted to space (uppermost panel). Clearsky fluxes in climate models are determined using Method II according to Cess and Potter (1987). Units $\mathrm{Wm}^{-2}$
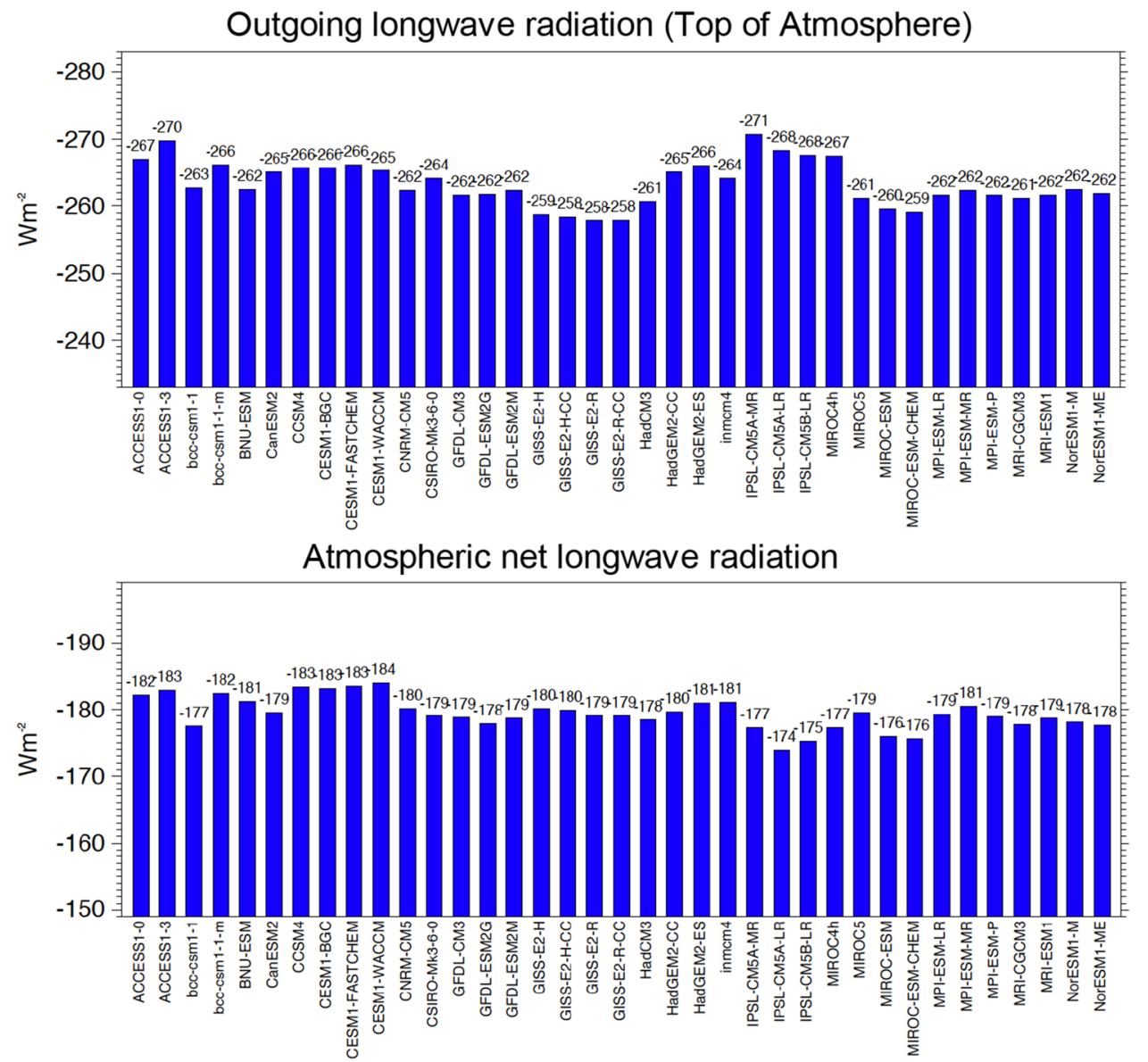

Surface net longwave radiation

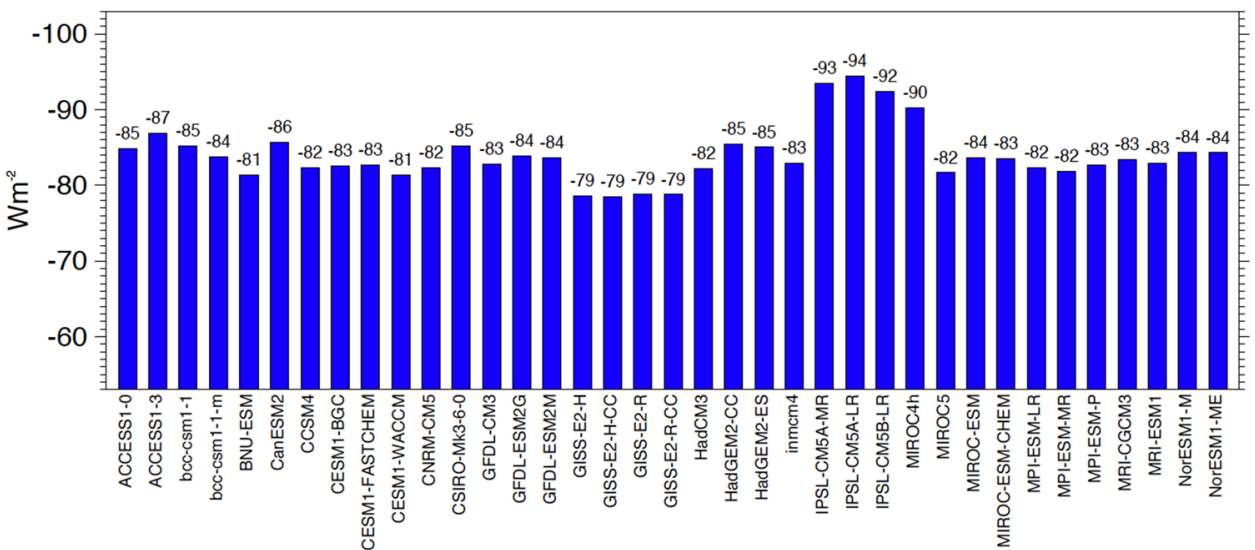

substantial differences amongst the global mean downward surface longwave clear-sky radiation of the various models shown in Fig. 9 (upper panel). The majority of the models (23 out of 37) overall overestimates the BSRN reference climatologies, whereas also strong underestimations in some of the models are evident. However, there are also numerous models that show hardly any overall biases in downward surface longwave clear-sky radiation, with 11 models having an overall bias of one $\mathrm{Wm}^{-2}$ or less. The mean and median biases of all models only amount to 1.1 and $1.4 \mathrm{Wm}^{-2}$, respectively.

\subsection{Best estimate for the global mean clear-sky downward surface longwave radiation}

As previously for the shortwave, we use in the following also the above longwave model biases to infer a best estimate of the global mean downward longwave clear-sky 
Fig. 9 Global annual mean downward longwave radiation at Earth's surface under present day climate calculated by 37 CMIP5 models under clearsky conditions (upper panel) and under all-sky conditions (lower panel). Clear-sky fluxes are determined using Method II according to Cess and Potter (1987). Units $\mathrm{Wm}^{-2}$
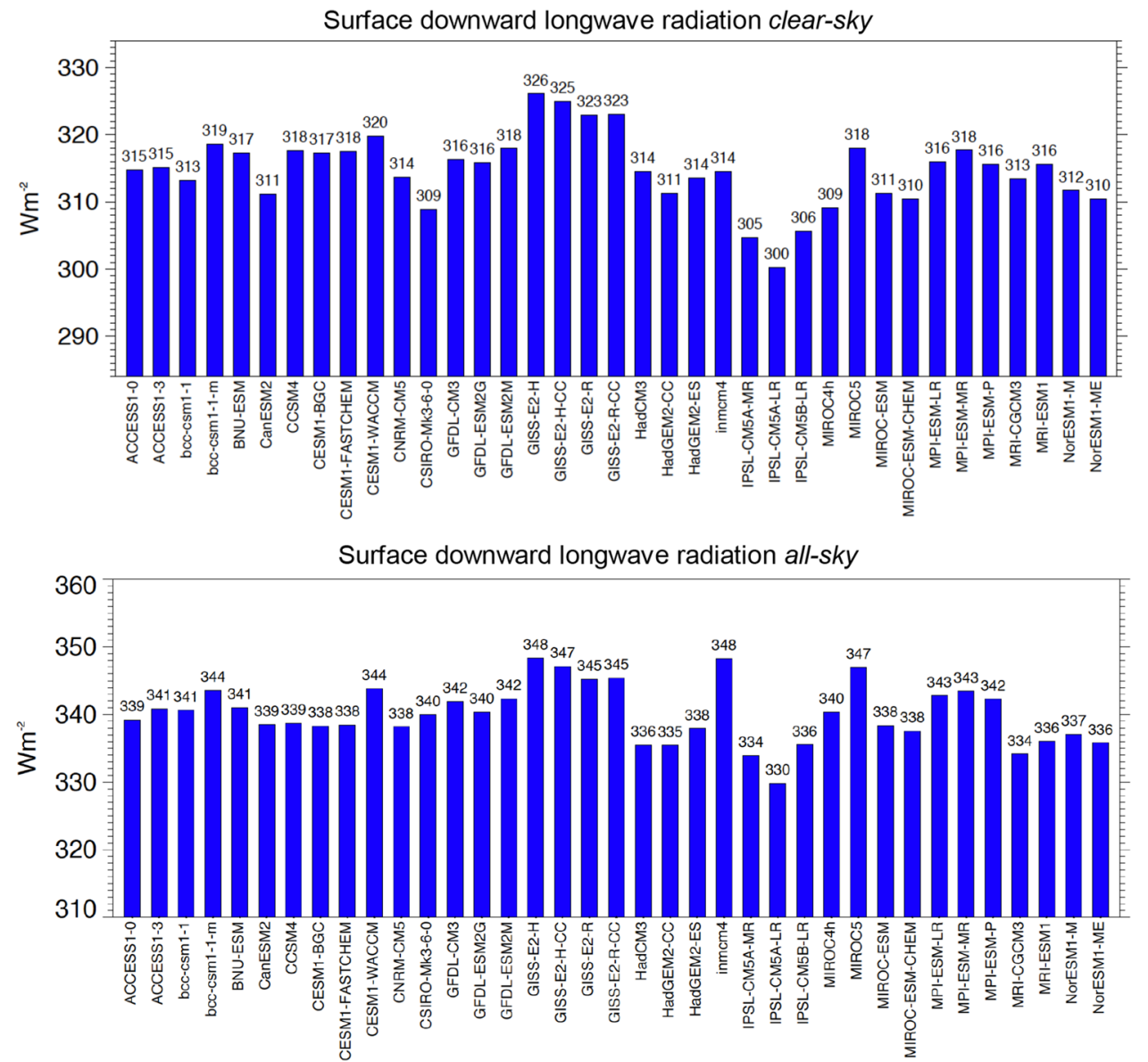

radiation at the Earth's surface. This is again achieved by relating the model biases to their respective global mean numbers, but now for the longwave rather than the shortwave downward surface clear-sky radiation. This is shown in Fig. 13, where for each model its overall bias in the climatological annual downward surface longwave clearsky radiation (as given in Fig. 12) is plotted against its corresponding global annual mean value (as given in Fig. 9 upper panel). As for the corresponding shortwave analysis, also in the longwave a tight relation between the two quantities can be noted, with a correlation coefficient of 0.88 . The stronger the overestimation (underestimation) of the downward surface longwave clear-sky radiation at the BSRN sites in a model, generally also the higher (lower) its corresponding global mean value. Again we then infer a "best estimate" for the global mean downward surface longwave clear-sky radiation from the linear regression at the intersect where the bias against the surface observations becomes zero (dashed lines in Fig. 13). Thereby we obtain a value of $313.7( \pm 0.9) \mathrm{Wm}^{-2}(2 \sigma$ uncertainty in the parentheses). Again the choice of the regression method (y-least squares and orthogonal regression) did not impact this value significantly (difference less than 0.2 $\mathrm{Wm}^{-2}$ ). We consider therefore a value around $314 \mathrm{Wm}^{-2}$ as best estimate for the global mean downward surface longwave clear-sky radiation.

The very same value of $314 \mathrm{Wm}^{-2}$ for this component was also obtained from the completely independent satellitederived product of CERES EBAF-surface (Kato et al. 2013). This increases confidence in the magnitude of this quantity derived here.

Similar to the shortwave best estimate in Sect. 4.3, we also enlarge the above $2 \sigma$ regression uncertainty range for the best estimate of the global mean downward surface longwave clear-sky radiation to accept all corresponding global means calculated by GCMs with marginal $\left(<1 \mathrm{Wm}^{-2}\right)$ biases shown in Fig. 13. Thereby we obtain a conservative uncertainty range from 311 to $317 \mathrm{Wm}^{-2}$ (rounded), which is indicated in Fig. 1.

\section{The global energy balance under cloud-free conditions}

Our best estimates of the global mean downward surface shortwave and longwave clear-sky radiation of 247 and 314 $\mathrm{Wm}^{-2}$, respectively, as derived in the above sections can then be combined with additional estimates of the TOA 

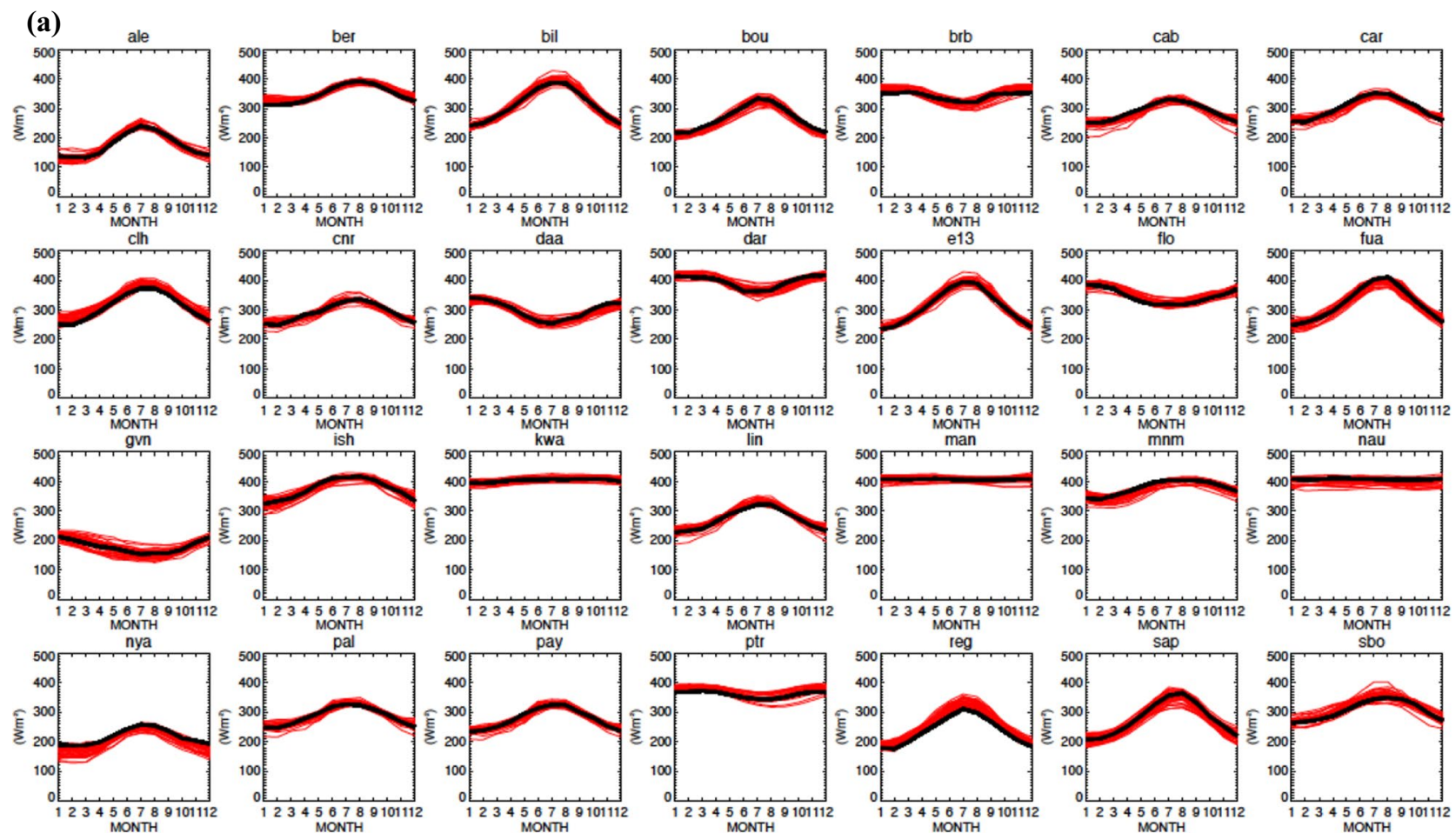

MONTH
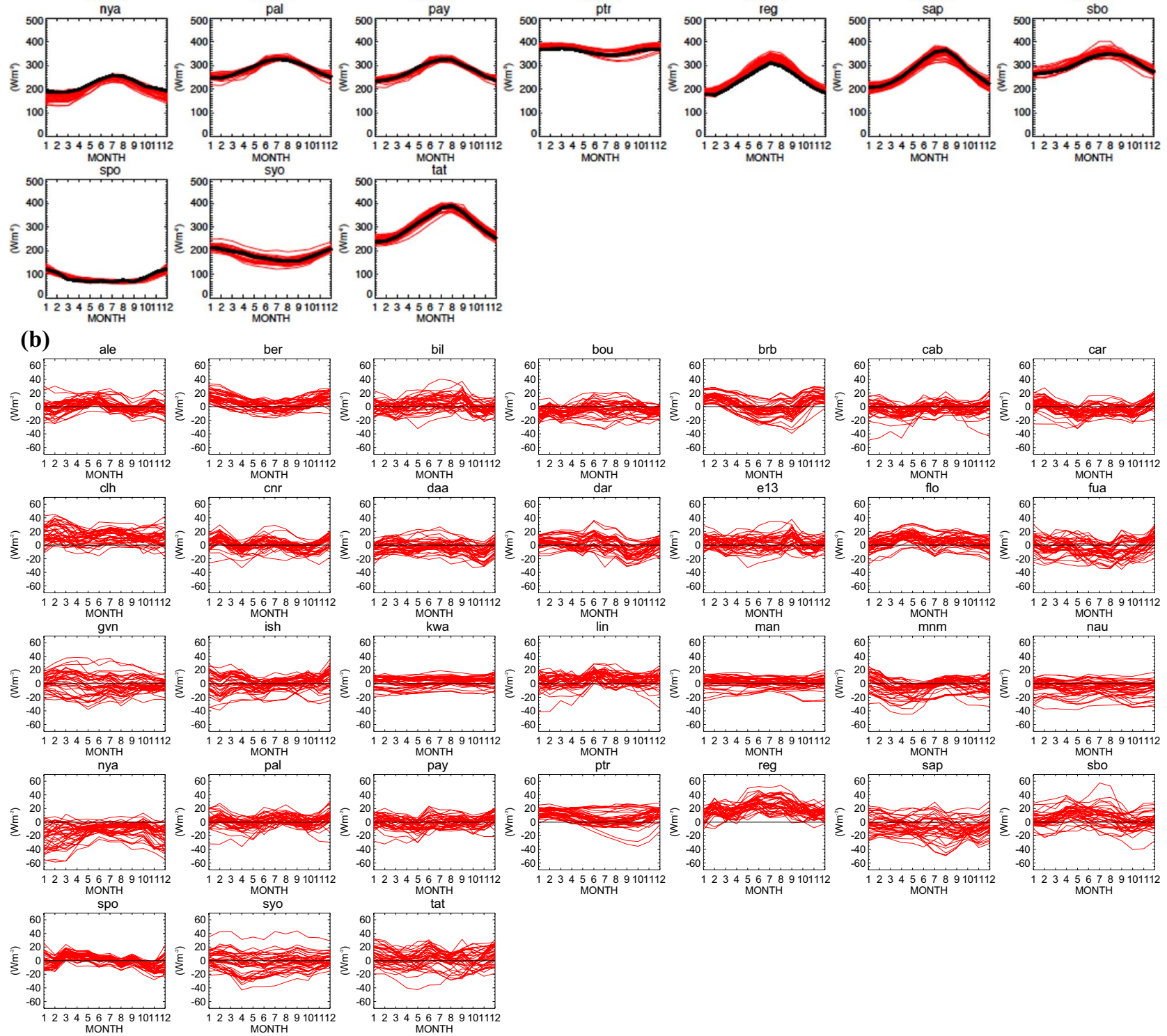
4Fig. 10 a Annual cycles of downward surface clear-sky longwave radiation climatologies measured at $31 \mathrm{BSRN}$ sites (black lines) and simulated by 37 CMIP5 climate models (red lines). b Differences between the individual model-calculated and observed annual cycles. Model and reference climatologies representative for the beginning of the 21th century. Station abbreviations explained in Table 1. Units $\mathrm{Wm}^{-2}$

clear-sky fluxes and surface radiative properties, to allow for a quantitative diagram of the global mean energy balance under cloud-free conditions (Fig. 1). Note that the clear-sky flux magnitudes in this diagram are representative for an atmospheric structure corresponding to all-sky conditions but with clouds removed. This view thus corresponds to the climate model-type representation of clear-sky fluxes (Method II according to Cess and Potter 1987), and enables a direct comparison with the clear-sky budgets obtained from GCM output. It further allows the isolation and quantification of the effects of clouds on the global mean Earth radiation budget, by comparing the all-sky fluxes with the clear-sky fluxes merely obtained by removing the clouds, but with otherwise identical atmospheric conditions.

The currently most accurate estimates for the global mean clear-sky fluxes at the TOA as presented in Fig. 1 can be obtained from the CERES EBAF dataset. We use here data from its latest Edition 4.0 (Loeb et al. 2018), where the global annual mean estimates for the reflected shortwave clear-sky and outgoing longwave clear-sky fluxes amount to 53 and $268 \mathrm{Wm}^{-2}$, respectively. These values, however, are aggregated only from cloud-free scenes, and thus, similarly to the BSRN shortwave clear-sky climatologies discussed previously, may slightly differ from the computation of clear-sky TOA fluxes in climate models (c.f. Sect. 4.2). The effect of sampling over all types of atmospheric conditions as in climate models, rather than only over truly cloud-free conditions in the calculation of the global mean clear-sky fluxes have been estimated by Kato et al. (2013) using the CERES EBAF framework. For the global mean shortwave reflected and outgoing longwave radiation at the TOA, Kato et al. (2013) estimate this sampling effect at 0.24 and $-1.25 \mathrm{Wm}^{-2}$, respectively (their Table 2 ). This signifies, that considering not just the (slightly drier) atmospheres as under true clear-sky conditions, but all atmospheric conditions (with somewhat more water vapor content) in the calculation of the clear-sky fluxes, results in a slightly lower outgoing clear-sky longwave and slightly higher reflected clear-sky shortwave radiation at the TOA, as one would expect. To keep the clear-sky energy balance diagram consistent with the GCM definition of clear-sky fluxes (Method II), we therefore slightly adjusted the CERES TOA global mean values for Fig. 1 with the abovementioned corrections of 0.24 and $-1.25 \mathrm{Wm}^{-2}$ in the shortwave and longwave, respectively. With these corrections, rounded to integers, the global mean clear-sky TOA shortwave reflected radiation remains at $53 \mathrm{Wm}^{-2}$, while the outgoing longwave radiation is slightly reduced to $267 \mathrm{Wm}^{-2}$ (Fig. 1). The associated uncertainties of these estimates amount to \pm 2 and \pm 3 $\mathrm{Wm}^{-2}$, respectively (Fig. 1) (Loeb et al. 2009). Combined with a global mean TOA insolation of $340 \mathrm{Wm}^{-2}$ (solar constant divided by four to obtain the average TOA insolation on a square meter on the Earth's sphere), the total amount of shortwave absorption under cloud-free conditions becomes $287 \mathrm{Wm}^{-2}$. Note that the cloud-free energy balance in the diagram shown in Fig. 1 is not the balance that Earth would achieve in equilibrium when no clouds could form. As mentioned above the diagram is rather representative for the GCM-type of clear-sky fluxes determined by removing the clouds but otherwise retaining the entire atmospheric structure. As a consequence, unlike in the all-sky case, the TOA budget is far from being balanced between shortwave clear-sky absorption $\left(287 \mathrm{Wm}^{-2}\right.$ ) and longwave clear-sky emission $\left(267 \mathrm{Wm}^{-2}\right.$ ). In the all-sky budget (Fig. 14 left, reproduced from Wild et al. 2015) the difference between these two quantities is largely remediated by the global net cloud radiative effect.

In our representation of the clear-sky energy balance we further retain the same radiative properties for the surface emission and surface albedo as in the discussion of the allsky budget in Wild et al. (2015), to be consistent. Using thus the global surface albedo of $13.5 \%$ from Wild et al. (2015) and the best estimate of $247 \mathrm{Wm}^{-2}$ for the global mean clear-sky shortwave downward radiation (Sect. 4.3), the global mean clear-sky surface shortwave absorption and reflection become 214 and $33 \mathrm{Wm}^{-2}$, respectively (Fig. 1). A detailed description of the derivation of the surface albedo value can be found in Wild et al. (2015). Strictly speaking, the surface albedo under clear-skies slightly differs from the one under all-sky conditions, because the incident radiation under clear-skies is more directional particularly over ocean. According to the dataset of CERES EBAF surface, this effect is, however, small on a global mean basis, at $0.3 \%$ (Kato et al. 2018, as can be derived from their Table 5). This corresponds to a change in surface shortwave reflection of only $0.7 \mathrm{Wm}^{-2}$, so that the magnitude of this flux rounded to integer remains at $33 \mathrm{Wm}^{-2}$ as given in Fig. 1 .

The amount of shortwave radiation absorbed within the cloud-free atmosphere can then be determined as residual between the cloud-free absorption of shortwave radiation in the total (TOA) climate system $\left(287 \mathrm{Wm}^{-2}\right)$ and at the surface $\left(214 \mathrm{Wm}^{-2}\right)$, and thus amounts to $73 \mathrm{Wm}^{-2}$. The $73 \mathrm{Wm}^{-2}$ of atmospheric shortwave clear-sky absorption closely match our previous estimates of this quantity which we obtained more than a decade ago based on older models and their biases against much fewer direct clear-sky observation (Wild et al. 2006). Two decades ago we estimated the global mean clear-sky atmospheric absorption similarly at $72 \mathrm{Wm}^{-2}$, not derived from clear-sky climatologies as they 
Fig. 11 Multi-model mean biases (model-observations) in annual mean downward surface clear-sky longwave radiation at 31 different BSRN sites (blue bars). The spread of individual model biases is further indicated with a vertical line covering \pm one standard deviation, and with the maximum positive and negative model biases given as triangle symbols. Station abbreviations explained in Table 1. Units $\mathrm{Wm}^{-2}$
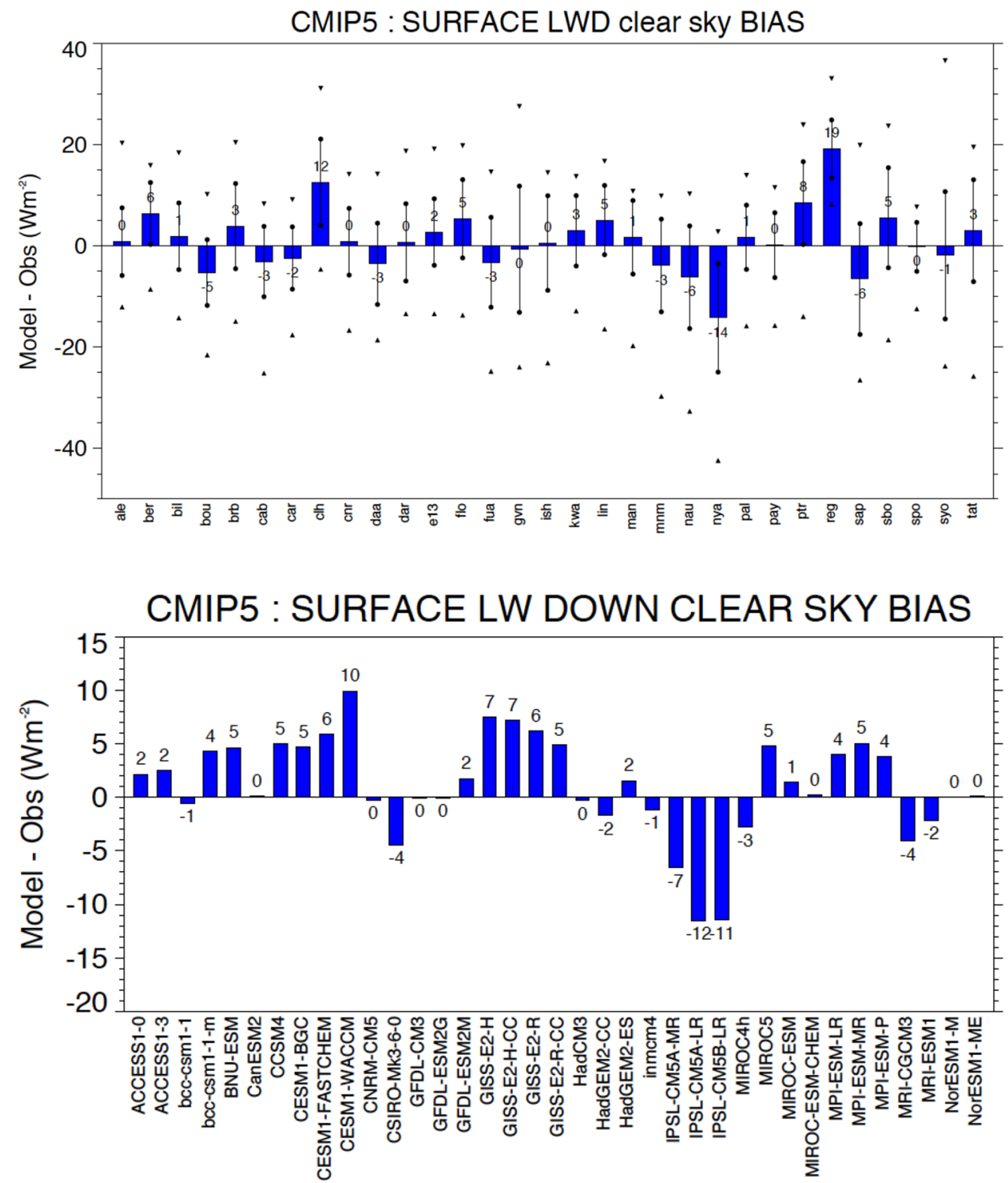

Fig. 12 Bias (model-observations) in annual mean downward clear-sky longwave radiation at Earth's surface calculated in 37 CMIP5 models averaged over 31 BSRN sites. Units $\mathrm{Wm}^{-2}$ were not available at the time, but from a stand-alone evaluation of the radiation codes under cloud-free conditions used in the ECHAM3 and ECHAM4 climate models (Wild et al. 1998). Also, from the completely independently derived CERES-EBAF Ed.4. satellite-derived dataset, the very same global mean atmospheric shortwave clear-sky absorption of $73 \mathrm{Wm}^{-2}$ has been determined (Kato et al. 2018) as in the present study. Further, in another independent approach, Kim and Ramanathan (2008) obtained a closely matching estimate of $72 \mathrm{Wm}^{-2}$ for this quantity, by integrating global satellite-derived data sets for aerosols, water vapor and total ozone with a Monte Carlo Aerosol-Cloud-Radiation (MACR) model.

This indicates that the estimate of the global mean shortwave absorption in the cloud-free atmosphere, somewhat above $70 \mathrm{Wm}^{-2}$, seems to be fairly robust. Thus, about $21 \%$ of the incoming shortwave radiation at the TOA, or about
$30 \%$ of the total amount of shortwave radiation absorbed by Earth may be absorbed in the cloud-free atmosphere.

The $73 \mathrm{Wm}^{-2}$ derived here for the global mean clear-sky shortwave atmospheric absorption are distinctly higher than some of the earlier estimates, and many of the simulated values of this quantity in GCMs, particularly in older models. This fits to the evidence for a lack of shortwave atmospheric absorption in many of the GCM radiation codes compared to line-by-line reference codes in radiation code intercomparison projects spanning more than two decades (Fouquart et al. 1991; Barker et al. 2003; Oreopoulos et al. 2012). The situation in GCMs has somewhat improved over the years. While the global mean clear-sky shortwave atmospheric absorption in some of the GCMs of the early 1990s did not even reach $60 \mathrm{Wm}^{-2}$ (Wild et al. 1998), this quantity was gradually enhanced in subsequent GCM generations, to 67 and $69 \mathrm{Wm}^{-2}$ in terms of multi-model means in the AMIPII 


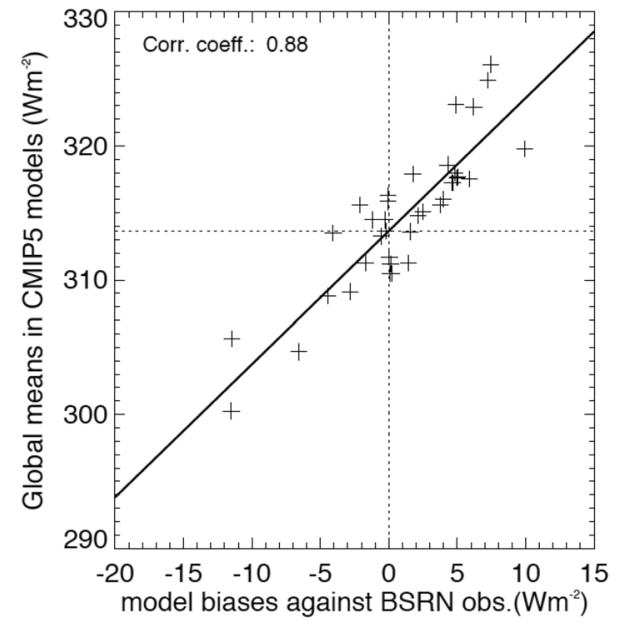

Fig. 13 Global annual mean surface downward longwave clear-sky radiation of 37 CMIP5 models (given as crosses) on the vertical axis versus their respective overall biases compared to 31 BSRN references on the horizontal axis. A "best estimate" for the downward surface longwave clear-sky radiation is inferred at the intersect between the linear regression line and the zero bias line. Units $\mathrm{Wm}^{-2}$

and CMIP3 model intercomparison projects, respectively (Wild et al. 2006), and finally to $71 \mathrm{Wm}^{-2}$ in the CMIP5 multi-model mean (Table 1). This development is in line with the notion of an overall improvement in the performance of more recent GCM radiation codes in the context of the Continual Intercomparison of Radiation Codes (CIRC) compared to earlier assessments (Oreopoulos et al. 2012). Increasing water vapor absorption, due to the improved description of the shortwave continuum absorption in the near-infrared windows and revised spectroscopic absorption coefficients, may favour this development (Radel et al. 2015; Paynter and Ramaswamy 2012, 2014; Kim and Ramanathan 2008). A more accurate description of the aerosol radiative properties in the GCM radiative transfer calculations may further contribute to the enhanced shortwave absorption (Ackerman et al. 2003; Kim and Ramanathan 2008). Note that now about half of the CMIP5 models calculate a clearsky atmospheric absorption that exceeds $70 \mathrm{Wm}^{-2}$ (Fig. 2 middle panel), and are thus in close agreement with the best estimate supported here. Yet there are still a number of CMIP5 models with a substantially lower clear-sky atmospheric absorption (Fig. 2 middle panel). This low absorption in some of these models may rather point to an inadequate implementation of known radiation physics in their radiation codes than to remaining genuine uncertainties in the representation of aerosols and the water vapor continuum.

In the longwave part of the cloud-free global energy balance diagram in Fig. 1, the surface fluxes consist of the downward longwave clear-sky radiation of $314 \mathrm{Wm}^{-2}$ (Sect. 5.3), and the upward longwave clear-sky surface radiation of $398 \mathrm{Wm}^{-2}$. This latter flux remains essentially the same as in the all-sky diagram (Fig. 14 left), since in the clear-sky we keep the surface and atmospheric properties identical to the all-sky except for the clouds as pointed out earlier, and the emission in the clear-sky thus comes from the surface with the same temperature as the all-sky. For a discussion of the justification of the $398 \mathrm{Wm}^{-2}$ for the all/ clear-sky longwave surface upward radiation the reader is referred to Wild et al. (2015). To be precise, there would still be a slight difference between the clear-sky and all-sky surface upward longwave radiation even under otherwise identical surface and atmospheric conditions. This is due to the fact the surface upward longwave flux contains not only the longwave emission from the Earth's surface, but added to this also a small contribution of the upward reflected fraction of downward longwave radiation. This reflection is neglected when the Earth's surface is assumed to be a perfect blackbody in the longwave, which then absorbs all incident
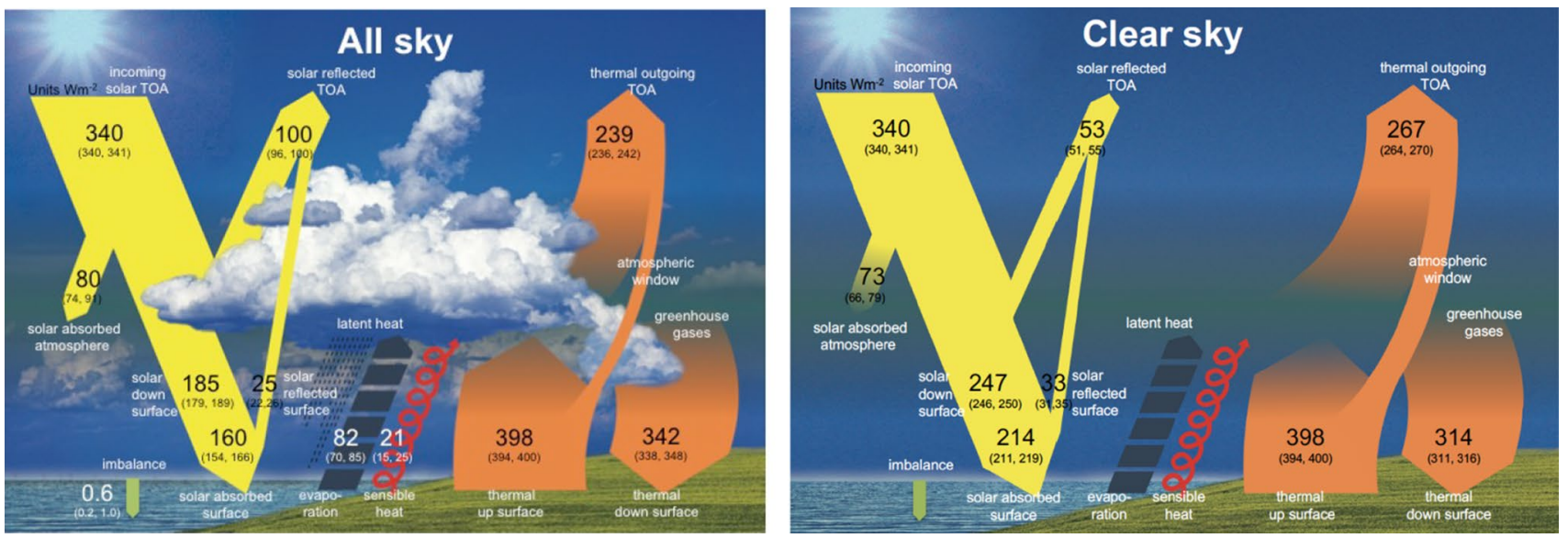

Fig. 14 Diagrams of the global mean energy balance of the Earth under all-sky (left) and clear-sky conditions (right), representing present day climate at the beginning of the 21 th century. All-sky diagram from Wild et al. (2015). Units $\mathrm{Wm}^{-2}$ 
longwave radiation. In reality the Earth's surface is globally indeed fairly close to a blackbody in the longwave, yet not perfectly, allowing for a few percent of the downward longwave fluxes to be reflected at the surface. However, since the all-sky and clear-sky downward longwave fluxes overall differ globally by only about $28 \mathrm{Wm}^{-2}$ (Table 2 and following Section below), the difference in the surface reflected longwave flux under clear- and all-sky conditions is less than $1 \mathrm{Wm}^{-2}$. This slight difference is thus neglected in Figs. 1 and 14, which display identical surface upward longwave fluxes under clear-sky and all-sky conditions. With a surface upward and downward clear-sky longwave radiation of 398 and $314 \mathrm{Wm}^{-2}$, this results in a best estimate for the surface net longwave clear-sky radiation of $-84 \mathrm{Wm}^{-2}$. This allows then also the estimation of the atmospheric clear-sky longwave net radiation (longwave atmospheric clear-sky divergence) at $-183 \mathrm{Wm}^{-2}$, calculated as a residual between the clear-sky outgoing and surface net longwave radiation of -267 and $-84 \mathrm{Wm}^{-2}$, respectively. The corresponding value for the atmospheric clear-sky longwave net radiation as derived in CERES-EBAF according to Kato et al. (2013) amounts to $-182 \mathrm{Wm}^{-2}$. Thus, as with the shortwave clear-sky atmospheric absorption, also our estimates for its longwave counterpart closely agree with the corresponding independent CERES-EBAF estimates.

\section{The global cloud radiative effects}

The clear-sky radiation balance derived in the previous section can then be used as a reference state to isolate and quantify the overall radiative effects of clouds, through a comparison with the corresponding all-sky radiation balance. Figure 14 contrasts the two radiation budgets, including clouds (left, as estimated in Wild et al. 2015) and excluding clouds (right, as estimated in the present study). This not only allows the estimation of the overall effects of clouds on the global mean radiation budget at the TOA, but also within the atmosphere and at the Earth' surface, as given in Fig. 15.

The TOA shortwave absorption under all-sky and clearsky conditions as determined from CERES-EBAF (Loeb et al. 2018), at 287 and $240 \mathrm{Wm}^{-2}$, respectively, differs by $47 \mathrm{Wm}^{-2}$. This suggests that the overall effect of clouds is to reduce the absorption of shortwave radiation in the climate system by $-47 \mathrm{Wm}^{-2}$ (TOA shortwave cloud radiative effect). Since the cloud radiative effect is defined as the difference between the all-sky and clear-sky fluxes, and since this indicates a cooling of the climate system, this value obtains a negative sign (Table 2; Fig. 15). Accordingly, the longwave cloud radiative effect at the TOA, as the difference between the outgoing longwave radiation under all-sky and clear-sky conditions determined from CERES-EBAF Edition 4.0 , becomes positive at $28 \mathrm{Wm}^{-2}$, since this states

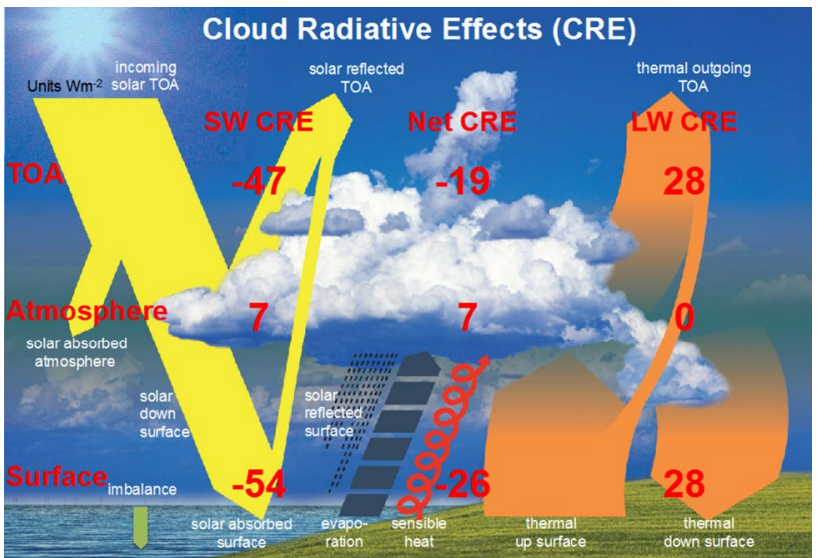

Fig. 15 Illustration of the magnitudes of the global mean shortwave, longwave and net (shortwave + longwave) cloud radiative effects (CRE) at the Top-of-Atmosphere (TOA), within the atmosphere and at the Earth's surface, determined as differences between the respective all-sky and clear-sky radiation budgets presented in Fig. 14. Units $\mathrm{Wm}^{-2}$

an energy gain for the climate system (Table 2; Fig. 15). The net (shortwave and longwave combined) cloud radiative effect at the TOA then results in an overall energy loss of $-19 \mathrm{Wm}^{-2}$ (Table 2; Fig. 15).

In addition to these widely published TOA cloud radiative effects, our study further allows the estimation of the global mean shortwave, longwave and net cloud radiative effects within the atmosphere and at the surface in a similar way, based on the respective all-sky and clear-sky estimates given in Fig. 14. At the surface the shading effects of clouds are estimated to reduce the downward shortwave radiation globally from 247 to $185 \mathrm{Wm}^{-2}$, thus by $-62 \mathrm{Wm}^{-2}$. In terms of absorbed (net) shortwave radiation at the Earth surface, the reduction by clouds amounts to $-54 \mathrm{Wm}^{-2}$ globally (from 214 to $160 \mathrm{Wm}^{-2}$ ), which corresponds to the net surface shortwave cloud radiative effect (Table 2; Fig. 15). On the other hand, clouds are estimated to enhance the global mean surface downward longwave radiation by 28 $\mathrm{Wm}^{-2}$, from 314 to $342 \mathrm{Wm}^{-2}$ (Table 2; Fig. 15). The same amount applies also to the net surface longwave cloud radiative effect (i.e. the cloud effect on the net longwave balance at the surface), since the all-sky and clear-sky upward longwave radiation is nearly identical within this framework (see discussion above). The surface net cloud radiative effect, defined as the sum of the surface net shortwave and longwave cloud effects, thus amounts then to $-26 \mathrm{Wm}^{-2}$ globally (Table 2).

In the atmosphere, the presence of clouds is estimated to enhance the shortwave absorption by $7 \mathrm{Wm}^{-2}$ from 73 $\mathrm{Wm}^{-2}$ (Fig. 14 right), to $80 \mathrm{Wm}^{-2}$ (Fig. 14 left). This is slightly higher than corresponding estimates obtained from most climate models and the CERES EBAF datasets, at 5 
$\mathrm{Wm}^{-2}$ between $60^{\circ} \mathrm{N}$ and $60^{\circ} \mathrm{S}$ (Hakuba et al. 2016), and 4.1 $\mathrm{Wm}^{-2}$ globally (Kato et al. 2018).

Since the cloud radiative effect on the longwave budget of the atmosphere is virtually zero (as a residual of surface and TOA longwave cloud radiative effects of $28 \mathrm{Wm}^{-2}$ each), the atmospheric net cloud radiative effect also remains at 7 $\mathrm{Wm}^{-2}$ (Table 2; Fig. 15).

These estimates for the surface, atmospheric and TOA global mean shortwave, longwave and net cloud radiative effects inferred here and illustrated in Fig. 15 can then be compared to the respective values determined in the various CMIP5 models (multi-model means in Table 2, individual models in Figs. 16, 17, 18). In the multi-model global mean, both shortwave and longwave cloud radiative effects agree within a few $\mathrm{Wm}^{-2}$ with the reference estimates derived here (Table 2). Global mean cloud radiative effects of individual models, however, vary substantially, with largest spreads and standard deviations occurring in the simulated surface estimates (Table 2; Figs. 16, 17, 18). This leads in some of the models to substantial deviations
Fig. 16 Global mean shortwave cloud radiative effects at the TOA (upper panel), within the atmosphere (middle panel) and at the surface (lower panel), defined as differences between the respective all-sky and clear-sky radiation budgets in individual CMIP5 models (red bars) and as derived as best estimate in the present study (black bars)
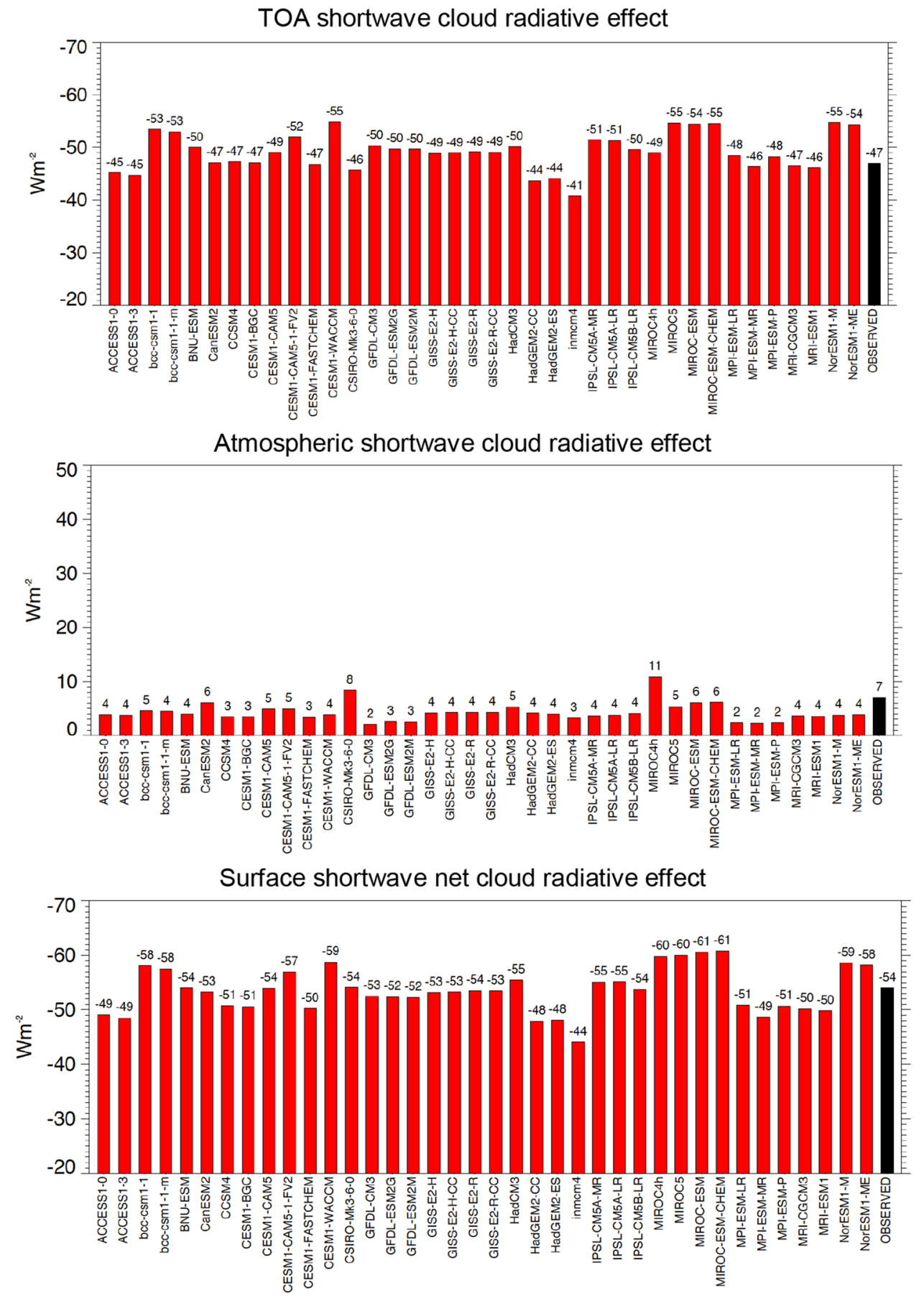
Fig. 17 Global mean longwave cloud radiative effects at the TOA (upper panel), within the atmosphere (middle panel) and at the surface (lower panel), defined as differences between the respective all-sky and clear-sky radiation budgets in individual CMIP5 models (red bars) and as derived as best estimate in the present study (black bars)
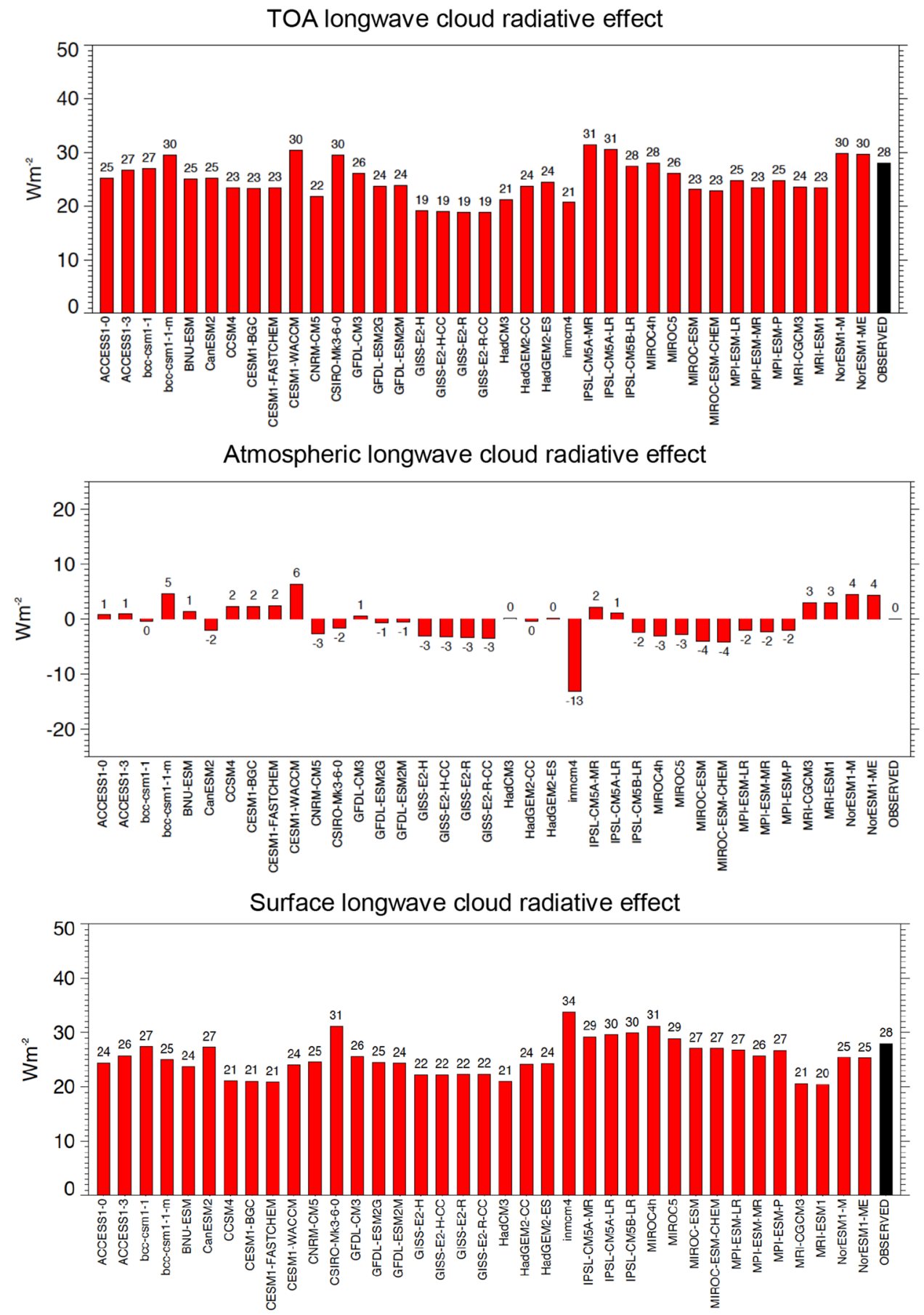

compared to the reference values developed here, in some cases exceeding $10 \mathrm{Wm}^{-2}$ on a global mean basis (Figs. 16, 17, 18). The deviations of the model-calculated surface cloud radiative effects from the reference values, together with the biases in their associated clear-sky fluxes, may give an indication for each individual model to what extent its cloud-free atmosphere or its clouds contribute to the overall biases noted in the simulated (all-sky) surface fluxes in previous studies.

\section{Summary and conclusions}

The global energy balance quantifies the distribution of radiative energy in the climate system. In previous studies we derived estimates for the magnitudes of the components of the "all-sky" global mean energy balance, taking into account the information provided by direct observations from surface and space as well as climate model 
Fig. 18 Global mean net (shortwave + longwave) cloud radiative effects at the TOA (upper panel), within the atmosphere (middle panel) and at the surface (lower panel), defined as differences between the respective all-sky and clear-sky radiation budgets in individual CMIP5 models (red bars) and as derived as best estimate in the present study (black bars)
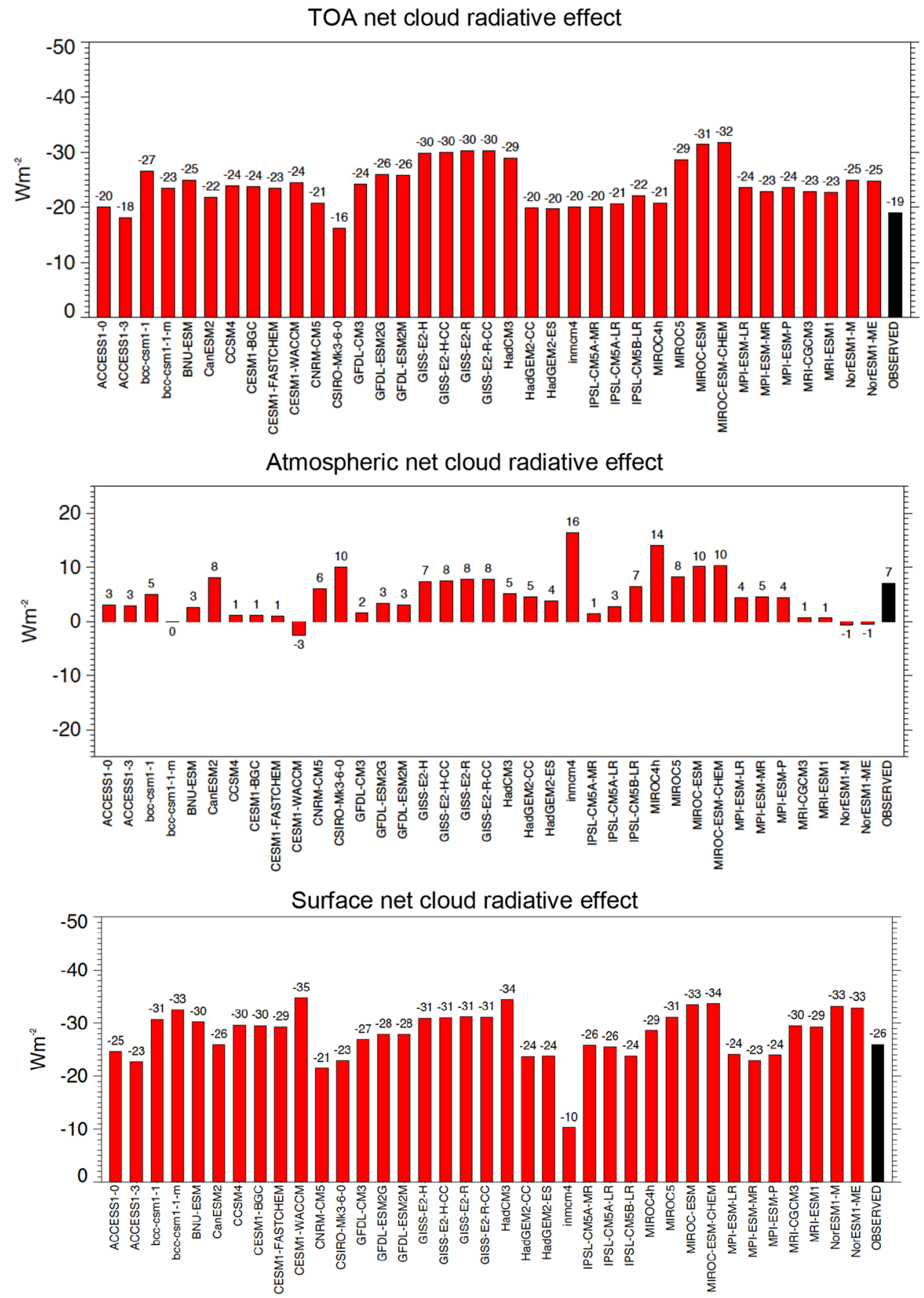

estimates (Wild et al. 2013, 2015). In the present study we made an attempt to derive complementary estimates for the global mean energy fluxes under cloud-free ("clearsky") conditions. While reference values for the energy fluxes in and out of the climate system under cloud-free conditions at the TOA are now available with high accuracy from satellite-based measurements (CERES EBAF), corresponding estimates for the atmospheric and surface clear-sky budgets are less straightforward to obtain. Yet such reference values are needed, since climate models still show considerable spreads in their simulated clearsky budgets, particularly at the Earth surface. As outlined in this study, these model spreads amount already in the global mean to as much as 16 and $24 \mathrm{Wm}^{-2}$ for the clearsky surface downward shortwave and longwave radiation, respectively, which may further amplify on regional, seasonal and diurnal scales. We thus made an attempt to better constrain these fluxes using newly-derived clear-sky reference climatologies obtained at more than 50 worldwide distributed anchor sites from BSRN. The assessment 
has been slightly complicated by the fact that the monthly shortwave clear-sky BSRN reference climatologies are derived from measurements under truly cloud-free conditions, whereas the GCMs clear-sky fluxes are calculated continuously at every time-step solely by removing the clouds, yet otherwise retaining the prevailing atmospheric composition associated with the cloudy conditions. The quantitative effects of these different clear-sky definitions were estimated by comparing in multi-century GCM control simulations the clear-sky irradiances in months with lowest cloud amounts to their corresponding climatological mean clear-sky irradiances. The effects of the different clear-sky definitions between models and observations, estimated at $2 \mathrm{Wm}^{-2}$ on average, were individually determined for each model and month and adjusted accordingly for a proper comparison with the reference climatologies.

The subsequent assessment of the CMIP5 clear-sky surface flux climatologies at the BSRN sites identified a number of models with overall biases of no more than $1-2 \mathrm{Wm}^{-2}$ in their shortwave and/or longwave downward flux climatologies. However there remain also a number of models with substantially larger overall flux biases, indicative of strong overestimations of the downward shortwave fluxes, as well as both overestimations and underestimations of the downward longwave fluxes, with systematic biases up to more than $10 \mathrm{Wm}^{-2}$ when averaged over all BSRN sites.

To derive best estimates for the global mean clear-sky radiative fluxes at the Earth's surface we then applied the approach presented in Wild et al. $(2013,2015)$ taking into account the bias structure of the 38 CMIP5 models with respect to the BSRN sites. The clear-sky radiative flux biases in the various models have thereby been linearly related to their respective global means. From the linear regression we inferred a best estimate (with zero bias against the surface observations) of $247 \mathrm{Wm}^{-2}$ for the global mean downward shortwave radiation at the surface under cloud-free conditions, and a corresponding surface absorption of $214 \mathrm{Wm}^{-2}$, assuming a global mean surface albedo of $13.5 \%$. Combined with a best estimate for the global net influx of shortwave radiation at the TOA under cloud-free skies from CERESEBAF of $287 \mathrm{Wm}^{-2}$, this leaves $73 \mathrm{Wm}^{-2}$ of shortwave radiation absorbed globally in the cloud-free atmosphere. This estimate nearly matches the completely independent estimates obtained from the state of the art satellite-retrieved dataset CERES-EBAF (Kato et al. 2013), as well as from a Monte Carlo Aerosol-Cloud-Radiation (MACR) model assimilated with satellite-derived input (Kim and Ramanathan 2008).

For the global mean downward longwave clear-sky radiation, a best estimate of $314 \mathrm{Wm}^{-2}$ was obtained, based on a regression between the GCM flux biases in downward longwave clear-sky radiation with respect to the BSRN references and their corresponding global means. Also this value matches the corresponding one from the independent CERES-EBAF satellite-retrieved dataset (Kato et al. 2013).

The close coincidence in the global magnitudes of key quantities describing the energy flows within the cloud-free climate system obtained in multiple independent approaches (based on surface observations and climate models as presented here on the one hand, and on state of the art satellitederived products on the other hand) increases confidence in the robustness of the derived magnitudes of these global numbers.

Accurate knowledge of the global radiation budget of the cloud-free atmosphere is a prerequisite to quantify the global cloud radiative effects, through a comparison with consistently derived "all-sky" global radiation budget estimates. Quantitative estimates of the global cloud radiative effects at the TOA, within the atmosphere and at the surface have thus been derived in the present study, which may also be of use in climate model assessments and tuning.

While the focus in the present study was on a first-order quantification of the overall (global long-term mean) clearsky budgets and cloud radiative effects, future studies should expand to assess these quantities in detail in their spatial as well as temporal variations.

Acknowledgements Work on the Global Energy Balance at ETH is supported by the Swiss National Science Foundation Grant 20002_159938/1 (Towards an improved understanding of the Global Energy Balance: temporal variations of solar radiation in the climate system). Atsumu Ohmura, Gert König-Langlo, and Amelie Driemel are highly acknowledged for establishing and maintaining the BSRN Archive over many years. Atsumu Ohmura's deep insight into the energy balance data is highly valued. The global energy balance diagrams shown in this paper were designed by Barbara Schär. We acknowledge the international modeling groups for providing their data for analysis, the Program for Climate Model Diagnosis and Intercomparison (PCMDI) for collecting and archiving the model data, the JSC/CLIVAR Working Group on Coupled Modeling (WGCM) and their Coupled Model Intercomparison Project (CMIP) and Climate Simulation Panel for organizing the model data analysis activity. The simulation with the climate model MPI-ESM-LR referred to in this study has been performed at the Swiss National Supercomputing Centre (CSCS) whose support is greatly acknowledged. We also wish to extend heartfelt appreciation to those individuals responsible for the long-term continuous operation and maintenance of the instruments and facilities that produced the quality observations used in this study; their diligent and dedicated efforts are often underappreciated.

Open Access This article is distributed under the terms of the Creative Commons Attribution 4.0 International License (http://creativeco mmons.org/licenses/by/4.0/), which permits unrestricted use, distribution, and reproduction in any medium, provided you give appropriate credit to the original author(s) and the source, provide a link to the Creative Commons license, and indicate if changes were made. 


\section{References}

Ackerman TP, Flynn DM, Marchand RT (2003) Quantifying the magnitude of anomalous solar absorption. J Geophys Res Atmos 108(D9):4273. https://doi.org/10.1029/2002jd002674

Barker HW, Stephens GL, Partain PT, Bergman JW, Bonnel B, Campana K, Clothiaux EE, Clough S, Cusack S, Delamere J, Edwards J, Evans KF, Fouquart Y, Freidenreich S, Galin V, Hou Y, Kato S, Li J, Mlawer E, Morcrette JJ, O'Hirok W, Raisanen P, Ramaswamy V, Ritter B, Rozanov E, Schlesinger M, Shibata K, Sporyshev P, Sun Z, Wendisch M, Wood N, Yang F (2003) Assessing 1d atmospheric solar radiative transfer models: interpretation and handling of unresolved clouds. J Clim 16(16):2676-2699. https://doi.org/10.1175/1520-0442(2003)016\%3C2676:Adasr $\mathrm{t} \% 3 \mathrm{E} 2.0 . \mathrm{Co} ; 2$

Brutsaert W (1975) On a derivable formula for long-wave radiation from clear skies. Water Resour Res 11:742-744. https://doi. org/10.1029/WR011i005p00742

Cess RD, Potter GL (1987) Exploratory studies of cloud radiative forcing with a general circulation model. Tellus 39A:460-473. https ://doi.org/10.1111/j.1600-0870.1987.tb00321.x

Collins WD, Ramaswamy V, Schwarzkopf MD, Sun Y, Portmann RW, Fu Q, Casanova SEB, Dufresne JL, Fillmore DW, Forster PMD, Galin VY, Gohar LK, Ingram WJ, Kratz DP, Lefebvre MP, Li J, Marquet P, Oinas V, Tsushima Y, Uchiyama T, Zhong WY (2006) Radiative forcing by well-mixed greenhouse gases: estimates from climate models in the intergovernmental panel on climate change (IPCC) fourth assessment report (A4). J Geophys Res Atmos 111(D14):Artn D14317. https://doi.org/10.1029/2005jd006713

Driemel A, Augustine JA, Behrens K, Colle S, Cox C, Cuevas-Agulló E, Denn FM, Duprat T, Fukuda M, Grobe H, Haeffelin M, Hyett N, Ijima O, Kallis A, Knap W, Kustov V, Long CN, Longenecker D, Lupi A, Maturilli M, Mimouni M, Ntsangwane L, Ogihara H, Olano X, Olefs M, Omori M, Passamani L, Pereira EB, Schmithüsen H, Schumacher S, Sieger R, Tamlyn J, Vogt R, Vuilleumier L, Xia X, Ohmura A, König-Langlo G (2018) Baseline Surface Radiation Network (BSRN): structure and data description (19922017). Earth Syst Sci Data. https://doi.org/10.5194/essd-2018-8

Fouquart Y, Bonnel B, Ramaswamy V (1991) Intercomparing shortwave radiation codes for climate studies. J Geophys Res Atmos 96(D5):8955-8968

Hakuba MZ, Folini D, Sanchez-Lorenzo A, Wild M (2013) Spatial representativeness of ground-based solar radiation measurements. J Geophys Res 118:8585-8597. https://doi.org/10.1002/jgrd.50673

Hakuba MZ, Folini D, Sanchez-Lorenzo A, Wild M (2014) Spatial representativeness of ground-based solar radiation measurementsextension to the full meteosat disk. J Geophys Res 119(20):1176011771. https://doi.org/10.1002/2014jd021946

Hakuba MZ, Folini D, Wild M (2016) On the zonal near-constancy of fractional solar absorption in the atmosphere. J Clim 29(9):34233440. https://doi.org/10.1175/Jcli-D-15-0277.1

Hakuba MZ, Folini D, Wild M, Long CN, Schaepman-Strub G, Stephens GL (2017) Cloud effects on atmospheric solar absorption in light of most recent surface and satellite measurements. Radiat Process Atmos Ocean. https://doi.org/10.1063/1.4975543

Hatzianastassiou N, Matsoukas C, Fotiadi A, Pavlakis KG, Drakakis E, Hatzidimitriou D, Vardavas I (2005) Global distribution of Earth's surface shortwave radiation budget. Atmos Chem Phys 5:2847-2867

IPCC (2013) Climate change 2013: the physical science basis. In: Contribution of working group I to the fifth assessment report of the Intergovernmental Panel on Climate Change. Cambridge, United Kingdom and New York, NY, USA

Kato S, Loeb NG, Rose FG, Doelling DR, Rutan DA, Caldwell TE, Yu LS, Weller RA (2013) Surface irradiances consistent with
CERES-derived top-of-atmosphere shortwave and longwave irradiances. J Clim 26(9):2719-2740. https://doi.org/10.1175/ Jcli-D-12-00436.1

Kato S, Rose FG, Rutan DA, Thorsen TJ, Loeb NG, Doelling DR, Huang XL, Smith WL, Su WY, Ham S-H (2018) Surface irradiances of edition 4.0 clouds and the earth's radiant energy system (CERES) energy balanced and filled (EBAF) data product. J Clim 31(11):4501-4527. https://doi.org/10.1175/JCLI-D-17-0523.1

Kiehl JT, Trenberth KE (1997) Earth's annual global mean energy budget. Bull Am Meteorol Soc 78(2):197-208

Kim DY, Ramanathan V (2008) Solar radiation budget and radiative forcing due to aerosols and clouds. J Geophys Res Atmos 113(D2):D02203. https://doi.org/10.1029/2007jd008434

L'Ecuyer TS, Beaudoing HK, Rodell M, Olson W, Lin B, Kato S, Clayson CA, Wood E, Sheffield J, Adler R, Huffman G, Bosilovich M, Gu G, Robertson F, Houser PR, Chambers D, Famiglietti JS, Fetzer E, Liu WT, Gao X, Schlosser CA, Clark E, Lettenmaier DP, Hilburn K (2015) The observed state of the energy budget in the early twenty-first century. J Clim 28(21):8319-8346. https:// doi.org/10.1175/Jcli-D-14-00556.1

Loeb NG, Wielicki BA, Doelling DR, Smith GL, Keyes DF, Kato S, Manalo-Smith N, Wong T (2009) Toward optimal closure of the Earth's top-of-atmosphere radiation budget. J Clim 22(3):748766. https://doi.org/10.1175/2008jcli2637.1

Loeb NG, Kato S, Su WY, Wong TM, Rose FG, Doelling DR, Norris JR, Huang XL (2012) Advances in understanding top-ofatmosphere radiation variability from satellite observations. Surv Geophys 33(3-4):359-385. https://doi.org/10.1007/S1071 2-012-9175-1

Loeb NG, Doelling DR, Wang HL, Su WY, Nguyen C, Corbett JG, Liang LS, Mitrescu C, Rose FG, Kato S (2018) Clouds and the earth's radiant energy system (CERES) energy balanced and filled (EBAF) top-of-atmosphere (TOA) edition-4.0 data product. J Clim 31(2):895-918. https://doi.org/10.1175/Jcli-D-17-0208.1

Long CN, Ackerman TP (2000) Identification of clear skies from broadband pyranometer measurements and calculation of downwelling shortwave cloud effects. J Geophys Res Atmos 105(D12):15609-15626. https://doi.org/10.1029/2000jd900077

Long CN, Gaustad KL (2004) The shortwave (sw) clear-sky detection and fitting algorithm: algorithm operational details and explanations, technical report arm tr-004. Atmos. Radiat. Measure. Program, U. S. Dep. of Energy, Washington, D. C. https://www.arm. gov/publications/tech_reports/arm-tr-004.1.pdf

Long CN, Turner DD (2008) A method for continuous estimation of clear-sky downwelling longwave radiative flux developed using ARM surface measurements. J Geophys Res Atmos. https://doi. org/10.1029/2008jd009936

Morcrette JJ (2002) Assessment of the ECMWF model cloudiness and surface radiation fields at the ARM SGP site. Mon Weather Rev 130(2):257-277

Nyeki S, Wacker S, Grobner J, Finsterle W, Wild M (2017) Revising shortwave and longwave radiation archives in view of possible revisions of the WSG and WISG reference scales: methods and implications. Atmos Meas Tech 10(8):3057-3071. https://doi. org/10.5194/amt-10-3057-2017

Ohmura A, Dutton EG, Forgan B, Frohlich C, Gilgen H, Hegner H, Heimo A, König-Langlo G, McArthur B, Muller G, Philipona R, Pinker R, Whitlock CH, Dehne K, Wild M (1998) Baseline Surface Radiation Network (BSRN/WCRP): new precision radiometry for climate research. Bull Am Meteorol Soc 79(10):2115-2136

Oreopoulos L, Mlawer E (2010) The continual intercomparison of radiation codes (CIRC) assessing anew the quality of gcm radiation algorithms. Bull Am Meteorol Soc 91(3):305-310. https:// doi.org/10.1175/2009bams2732.1

Oreopoulos L, Mlawer E, Delamere J, Shippert T, Cole J, Fomin B, Iacono M, Jin ZH, Li JN, Manners J, Raisanen P, Rose F, Zhang 
YC, Wilson MJ, Rossow WB (2012) The continual intercomparison of radiation codes: results from phase I. J Geophys Res Atmos 117:Artn D06118. https://doi.org/10.1029/2011jd016821

Ott P (2017) Variation of solar radiation under cloud free conditions at BSRN sites in CMIP5 models. Master Thesis, University of Zurich, Zurich, Switzerland

Paynter D, Ramaswamy V (2012) Variations in water vapor continuum radiative transfer with atmospheric conditions. J Geophys Res Atmos 117:Artn D16310. https://doi.org/10.1029/2012jd017504

Paynter D, Ramaswamy V (2014) Investigating the impact of the shortwave water vapor continuum upon climate simulations using GFDL global models. J Geophys Res Atmos 119(18):10720 10737. https://doi.org/10.1002/2014jd021881

Pfeifroth U, Sanchez-Lorenzo A, Manara V, Trentmann J, Hollmann R (2018) Trends and variability of surface solar radiation in Europe based on surface- and satellite-based data records. J Geophys Res Atmos 123(3):1735-1754. https://doi.org/10.1002/2017jd027418

Pincus R, Mlawer EJ, Oreopoulos L, Ackerman AS, Baek S, Brath M, Buehler SA, Cady-Pereira KE, Cole JNS, Dufresne JL, Kelley M, Li JN, Manners J, Paynter DJ, Roehrig R, Sekiguchi M, Schwarzkopf DM (2015) Radiative flux and forcing parameterization error in aerosol-free clear skies. Geophys Res Lett 42(13):5485-5492. https://doi.org/10.1002/2015g1064291

Potter GL, Cess RD (2004) Testing the impact of clouds on the radiation budgets of 19 atmospheric general circulation models. J Geophys Res Atmos 109(D2):D02106. https://doi.org/10.1029/2003j d004018

Potter GL, Slingo JM, Morcrette JJ, Corsetti L (1992) A modeling perspective on cloud radiative forcing. J Geophys Res Atmos 97(D18):20507-20518. https://doi.org/10.1029/92jd01909

Radel G, Shine KP, Ptashnik IV (2015) Global radiative and climate effect of the water vapour continuum at visible and near-infrared wavelengths. Q J R Meteorol Soc 141(688):727-738. https://doi. org/10.1002/qj.2385

Ramanathan V (1987) The role of earth radiation budget studies in climate and general-circulation research. J Geophys Res Atmos 92(D4):4075-4095. https://doi.org/10.1029/Jd092id04p04075

Stephens GL, Li JL, Wild M, Clayson CA, Loeb N, Kato S, L'Ecuyer T, Stackhouse PW, Lebsock M, Andrews T (2012) An update on Earth's energy balance in light of the latest global observations. Nat Geosci 5(10):691-696. https://doi.org/10.1038/Ngeo1580

Takahashi HG (2018) A systematic tropospheric dry bias in the tropics in CMIP5 models: relationship between water vapor and rainfall characteristics. J Meteorol Soc Jpn 96:415-423. https://doi. org/10.2151/jmsj.2018-046

Trenberth KE, Fasullo JT (2012) Tracking earth's energy: from El Nino to global warming. Surv Geophys 33(3-4):413-426. https://doi. org/10.1007/S10712-011-9150-2
Trenberth KE, Fasullo JT, Kiehl J (2009) Earth's global energy budget. Bull Am Meteorol Soc 90(3):311. https://doi.org/10.1175/2008b ams2634.1

Wang HL, Su WY (2013) Evaluating and understanding top of the atmosphere cloud radiative effects in intergovernmental panel on climate change (IPCC) fifth assessment report (AR5) coupled model intercomparison project phase 5 (CMIP5) models using satellite observations. J Geophys Res Atmos 118(2):683-699. https://doi.org/10.1029/2012jd018619

Wielicki BA, Barkstrom BR, Harrison EF, Lee RB, Smith GL, Cooper JE (1996) Clouds and the earth's radiant energy system (CERES): an earth observing system experiment. Bull Am Meteorol Soc 77(5):853-868

Wild M (2008) Short-wave and long-wave surface radiation budgets in GCMs: a review based on the IPCC-AR4/CMIP3 models. Tellus A 60(5):932-945. https://doi.org/10.1111/J.1600-0870.2008.00342 .X

Wild M (2009) Global dimming and brightening: a review. J Geophys Res Atmos 114:D00d16. https://doi.org/10.1029/2008jd011470

Wild M, Ohmura A, Gilgen H, Roeckner E (1995) Validation of general-circulation model radiative fluxes using surface observations. J Clim 8(5):1309-1324

Wild M, Ohmura A, Gilgen H, Roeckner E, Giorgetta M, Morcrette JJ (1998) The disposition of radiative energy in the global climate system: GCM-calculated versus observational estimates. Clim Dyn 14(12):853-869

Wild M, Long CN, Ohmura A (2006) Evaluation of clear-sky solar fluxes in gcms participating in AMIP and IPCC-AR4 from a surface perspective. J Geophys Res Atmos 111(D1):D01104. https ://doi.org/10.1029/2005jd006118

Wild M, Folini D, Schar C, Loeb N, Dutton EG, König-Langlo G (2013) The global energy balance from a surface perspective. Clim Dyn 40(11-12):3107-3134. https://doi.org/10.1007/S0038 2-012-1569-8

Wild M, Folini D, Hakuba MZ, Schar C, Seneviratne SI, Kato S, Rutan D, Ammann C, Wood EF, Konig-Langlo G (2015) The energy balance over land and oceans: an assessment based on direct observations and CMIP5 climate models. Clim Dyn 44(11-12):33933429. https://doi.org/10.1007/s00382-014-2430-z

Wild M, Ohmura A, Schar C, Muller G, Folini D, Schwarz M, Hakuba MZ, Sanchez-Lorenzo A (2017) The Global Energy Balance Archive (GEBA) version 2017: a database for worldwide measured surface energy fluxes. Earth Syst Sci Data 9(2):601-613. https://doi.org/10.5194/essd-9-601-2017 